University of Wollongong

Research Online

Faculty of Engineering and Information

Faculty of Engineering and Information

Sciences - Papers: Part B

Sciences

2018

\title{
Mechanical properties of micro-steel fibre reinforced magnesium potassium phosphate cement composite
}

Hu Feng

Zhengzhou University, hfeng@uow.edu.au

M Neaz Sheikh

University of Wollongong, msheikh@uow.edu.au

Muhammad N. S Hadi

University of Wollongong, mhadi@uow.edu.au

Danying Gao

Zhengzhou University, Henan University of Engineering

Jun Zhao

Zhengzhou University

Follow this and additional works at: https://ro.uow.edu.au/eispapers1

Part of the Engineering Commons, and the Science and Technology Studies Commons

Research Online is the open access institutional repository for the University of Wollongong. For further information contact the UOW Library: research-pubs@uow.edu.au 


\title{
Mechanical properties of micro-steel fibre reinforced magnesium potassium phosphate cement composite
}

\author{
Abstract \\ This paper presents the mechanical properties of micro-steel fibre (MSF) reinforced magnesium \\ potassium phosphate cement (MPPC) composites with multi-composite retarder. The compressive \\ strength, flexural strength, flexural toughness and flexural ductility of the MSF reinforced MPPC \\ composite (MSFRMC) were experimentally explored. The variables of the experiment included sand- \\ cement mass ratio, water-cement mass ratio, curing time and fibre volume fraction. In addition, the effect \\ of different types of cement on the mechanical properties of MSF reinforced composites was \\ investigated. It was found that with the increase of water content in the MPPC paste, the average \\ compressive strength, flexural strength and flexural toughness of MSFRMC decreased significantly and \\ the ductility of MSFRMC increased slightly. With the increase of MPPC content in the paste, the flexural \\ toughness of MSFRMC increased significantly and the flexural ductility of MSFRMC increased moderately. \\ With the increase of the addition of MSF, the compressive strength, flexural strength, flexural toughness \\ and flexural ductility of MSFRMC improved significantly. The compressive strength, flexural strength, \\ flexural toughness and flexural ductility of MSFRMC were high at the early stage of curing, especially \\ during the first 3 days. The addition of MSF in MPPC composite improved the compressive strength, \\ flexural toughness and flexural ductility significantly more than the addition of MSF in sulphoaluminate \\ cement and ordinary Portland cement composites.
}

\section{Keywords}

reinforced, fibre, micro-steel, properties, mechanical, phosphate, potassium, composite, magnesium, cement

\section{Disciplines}

Engineering | Science and Technology Studies

\section{Publication Details}

Feng, H., Sheikh, M. Neaz., Hadi, M. N. S., Gao, D. \& Zhao, J. (2018). Mechanical properties of micro-steel fibre reinforced magnesium potassium phosphate cement composite. Construction and Building Materials, 185 423-435. 
7

8

9

10

\section{Mechanical properties of micro-steel fibre reinforced magnesium} potassium phosphate cement composite

3

Hu Feng ${ }^{\mathrm{a}} \quad$ M. Neaz Sheikh ${ }^{\mathrm{b}} \quad$ Muhammad N.S. Hadi $^{\mathrm{b}} *$ Danying Gao $^{\mathrm{a}}$ Jun Zhao $^{\mathrm{a}}$

(1)

6 (1)

${ }^{\mathrm{b}}$ School of Civil, Mining and Environmental Engineering, University of Wollongong, NSW 2522, Australia

10

\section{Correspondence:}

\section{Muhammad N.S. Hadi}

School of Civil, Mining and Environmental Engineering University of Wollongong, NSW 2522, Australia

E-mail: mhadi@uow.edu.au

Telephone:

\footnotetext{
* Corresponding author
} 


\section{Mechanical properties of micro-steel fibre reinforced magnesium potassium phosphate cement composite}

Abstract: This paper presents the mechanical properties of micro-steel fibre (MSF) reinforced magnesium potassium phosphate cement (MPPC) composites with multi-composite retarder. The compressive strength, flexural strength, flexural toughness and flexural ductility of the MSF reinforced MPPC composite (MSFRMC) were experimentally explored. The variables of the experiment included sand-cement mass ratio, water-cement mass ratio, curing time and fibre volume fraction. In addition, the effect of different types of cement on the mechanical properties of MSF reinforced composites was investigated. It was found that with the increase of water content in the MPPC paste, the average compressive strength, flexural strength and flexural toughness of MSFRMC decreased significantly and the ductility of MSFRMC increased slightly. With the increase of MPPC content in the paste, the flexural toughness of MSFRMC increased significantly and the flexural ductility of MSFRMC increased moderately. With the increase of the addition of MSF, the compressive strength, flexural strength, flexural toughness and flexural ductility of MSFRMC improved significantly. The compressive strength, flexural strength, flexural toughness and flexural ductility of MSFRMC were high at the early stage of curing, especially during the first 3 days. The addition of MSF in MPPC composite improved the compressive strength, flexural toughness and flexural ductility significantly more than the addition of MSF in sulphoaluminate cement and ordinary Portland cement composites.

Keywords: Magnesium Potassium Phosphate Cement; Micro-steel fibre; Strength; Flexural toughness. 


\section{Research Highlights}

56 Mechanical properties of MSF reinforced MPPC composites have been presented

57 Compressive strength and flexural strength of MSFRMC have been investigated

58 Flexural toughness and flexural ductility of MSFRMC have been investigated

59 Compressive and flexural strengths of MSFRMC were high at early stage of curing

60 Reinforcing effect of MSF was higher in MPPC composites than in SAC and OPC composites

61 
62

\section{Introduction}

Magnesium Phosphate Cement (MPC) is a new type of binder which forms the chemical bond through an acid-base reaction between magnesia and phosphate. The MPC was first discovered and developed as dental cement in the late $19^{\text {th }}$ century [1-3]. Since 1970 , MPC has been used to prepare light magnesium cement foamed material [4] and building materials [5]. It has also been used to stabilize and solidify wastes $[6,7]$. Compared to the Portland cement, the MPC possesses excellent engineering properties including very rapid setting time, high early strength, low shrinkage, high bond strength, high abrasion resistance, high durability and ability to set and harden at temperatures as low as $-20^{\circ} \mathrm{C}$. Therefore, it has the potential to be used in the rapid repair of airfield runways, bridges and highways. The research on MPC as a repair and quick construction material has received increased attention [8-10].

The ammonium dihydrogen phosphate $\left(\mathrm{NH}_{4} \mathrm{H}_{2} \mathrm{PO}_{4}\right)$, as the bisalt of the acid-base reaction, was used to prepare MPC [11-15]. However, the limitation of using $\mathrm{NH}_{4} \mathrm{H}_{2} \mathrm{PO}_{4}$ is that some ammonia was released as a gas during the reaction of magnesia and $\mathrm{NH}_{4} \mathrm{H}_{2} \mathrm{PO}_{4}[8]$. The released ammonia created an unpleasant environment. Potassium dihydrogen phosphate $\left(\mathrm{KH}_{2} \mathrm{PO}_{4}\right)$ has recently been identified as a good candidate for replacing ammonium phosphate [16]. Previous research on MPC prepared with $\mathrm{KH}_{2} \mathrm{PO}_{4}$ indicated that the performance of composite was mainly influenced by the reactivity of magnesia, the molar ratio of magnesia-phosphate $(\mathrm{M} / \mathrm{P})$, and the retarder and water content [17-22]. Usually, borax $\left(\mathrm{Na}_{2} \mathrm{~B}_{4} \mathrm{O}_{7} \cdot 10 \mathrm{H}_{2} \mathrm{O}\right)$ is used as a retarder to control the fast reaction. However, the excessive use of the borax resulted in a decrease of the compressive strength [23]. Addition of a small amount of sodium tripolyphosphate $\left(\mathrm{Na}_{5} \mathrm{P}_{3} \mathrm{O}_{10}\right)$ or sodium dihydrogen phosphate dodecahydrate $\left(\mathrm{NaH}_{2} \mathrm{PO}_{4} \cdot 12 \mathrm{H}_{2} \mathrm{O}\right)$ improved the mechanical properties and controlled the setting time as well [24, 25]. Due to this positive effect of $\mathrm{NaH}_{2} \mathrm{PO}_{4} \cdot 12 \mathrm{H}_{2} \mathrm{O}$, the setting time and compressive strength of MPC cured for more than 28 days improved significantly by the addition of a certain amount of multicomposite retarder (CR), which consisted of borax, sodium dihydrogen phosphate dodecahydrate and calcium chloride [26]. 
90 Although a significant number of studies were carried out on the development of MPC, the MPC-

91 based composites are typically brittle. Because of the high volume of cementitious compounds, the MPC-based matrix is more brittle than the Portland cement and sulphoaluminate cement (SAC) based matrices [27]. One of the most effective ways of reducing the brittleness and improving the toughness is the addition of steel fibres in the matrix [28]. The MPC can be used as a binder in fibre reinforced composites. The tensile chemical bond tests revealed better bonding of steel fibre with magnesia phosphate matrix compared to accelerated calcium aluminate $[29,30]$. The steel fibre may improve significantly the strength of the MPC mortar and reduce the shrinkage of the MPC [31]. Also, the addition of the proper type and amount of steel fibres into MPC-based matrix lead to composites with elastic-plastic or deflection hardening behaviour under bending. Not only the quick setting and high early strength are essential requirements but also a high ductility is needed to guarantee the long life of the repair. Hence the steel fibre reinforced MPC-based composites are considered suitable as quick repair materials [32]. While some studies provided preliminary results on the feasibility of steel fibre reinforced MPC-based composites, a large number of research investigations are still warranted, which include optimization of the matrix, determination of the type and the volume fraction of fibre, and improvement of the durability. Compared to the ordinary steel fibre, the micro-steel fibre (MSF) has the advantages of larger number fibres per kilogram, higher strength and easier dispersion. It was found that the addition of MSF improved the tensile strength, flexural strength and toughness of the Reactive Powder Concrete with an ultra-high compressive strength of more than $100 \mathrm{MPa}$ [33-35]. Hence, MSF has the potential to improve the toughness and ductility of MPC composites.

This paper describes the strength and toughness of MSF reinforced Magnesium Potassium Phosphate cement (MPPC) based composites which include a multi-composite retarder. This composite is termed as MSF reinforced MPPC composite (MSFRMC). The variables investigated include mixture design parameter (water-cement mass ratio and sand-cement mass ratio), fibre volume fraction and curing time. Also, the compressive strength and toughness characteristics of MSF reinforced MPPC, SAC and ordinary Portland cement (OPC) based composites were compared. 


\section{Experimental program}

119

120

121

122

\subsection{Materials}

The Magnesium Potassium Phosphate Cement (MPPC) was prepared from a mixture of calcined magnesia $(\mathrm{MgO})$, potassium dihydrogen phosphate $\left(\mathrm{KH}_{2} \mathrm{PO}_{4}\right)$ and multi-composite retarder $(\mathrm{CR})$. The multi-composite retarder consisted of borax $\left(\mathrm{Na}_{2} \mathrm{~B}_{4} \mathrm{O}_{7} \cdot 10 \mathrm{H}_{2} \mathrm{O}\right)$, disodium hydrogen phosphate dodecahydrate $\left(\mathrm{Na}_{2} \mathrm{HPO}_{4} \cdot 12 \mathrm{H}_{2} \mathrm{O}\right)$ and calcium chloride $\left(\mathrm{CaCl}_{2}\right)$. The calcined magnesia was sourced from Zhengyang Casting Material Company of Xinmi, Henan, China [36] in the form of Dead Burnt Magnesia powder with a specific surface area of $639 \mathrm{~m}^{2} / \mathrm{kg}$ and calcined at $1200^{\circ} \mathrm{C}$ for $6 \mathrm{~h}$. The detail oxide composition of calcined magnesia is provided in Table 1. The industrial grade potassium dihydrogen phosphate $\left(\mathrm{KH}_{2} \mathrm{PO}_{4}\right)$ with a purity of $98 \%$, particle size of $180-385 \mu m$ and relative density of 2.338 was supplied by Weitong Chemical Co., Ltd of Wujiang, Jiangsu, China [37]. The industrial grade borax $\left(\mathrm{Na}_{2} \mathrm{~B}_{4} \mathrm{O}_{7} \cdot 10 \mathrm{H}_{2} \mathrm{O}\right)$ with a purity of $95 \%$ and particle size of $80-220 \mu m$ was provided by Banda Technology Co., Ltd. of Liaoning, China [38]. The analytical grade disodium hydrogen phosphate dodecahydrate $\left(\mathrm{Na}_{2} \mathrm{HPO}_{4} \cdot 12 \mathrm{H}_{2} \mathrm{O}\right)$ with a purity of $99 \%$ and calcium chloride $\left(\mathrm{CaCl}_{2}\right)$ with a purity of $96 \%$ were provided by Kermel Chemical Reagent Co., Ltd. of Tianjin, China [39]. Tap water, natural river sand with fineness modulus of 2.06 and micro-steel fibre (MSF) with hooked ends were also used in this study. The properties of MSF provided by the manufacturer [40] are detailed in Table 2. As shown in Figure 1, the length of the MSF is $13 \mathrm{~mm}$.

The SAC of Grade P.O 42.5R according to GB20472-2006 [41] and the OPC of Grade P.O 42.5 according to GB175-2007 [42] used in this study were obtained from Anda Special Cement Co., Ltd. Group of Yicheng, China [43] and Mengdian Group Cement Co., Ltd of Henan, China [44], respectively. 


\subsection{Mixture proportions}

143 The mole ratio of $\mathrm{MgO}$ to $\mathrm{KH}_{2} \mathrm{PO}_{4}$ was fixed at $4(\mathrm{M} / \mathrm{P}=4)$ in all MPPC mixtures. The dosage of 144 multi-composition retarder was $9.0 \%$ of $\mathrm{MgO}$ by mass for all MPPC composites. The mass ratio of 145 borax, disodium hydrogen phosphate dodecahydrate and calcium chloride in the multi-composition retarder was 1:3:1. The MPPC consisted of $\mathrm{MgO}$ and $\mathrm{KH}_{2} \mathrm{PO}_{4}$. The addition of MSF was by volume. The SAC and OPC based composites were also prepared to compare the strength characteristics, flexural toughness and ductility. The mixture proportions of MPPC, SAC and OPC based composites are listed in Table 3.

As shown in Table 3, there are three components for the group names of the specimens. The first component of the group names is about the type of cement, where the " $\mathrm{M}$ ", "S" and "P" represent MPPC, SAC and OPC, respectively. The second component of the group names is about the variables of tests, where the "S/C", "W/C" and "F" represent the sand-cement mass ratio, water-cement mass ratio and fibre volume fraction, respectively. For the third component of the group names, the numbers represent the values of the variables of the second components of the group names. The default values of the sand-cement mass ratio and fibre volume fraction for all the composites are 1.0 and $1.2 \%$, respectively. The default values of water-cement mass ratio for MPPC, SAC and OPC based composites are $0.16,0.35$ and 0.37 , respectively. When the values of one of the variables are changing, the values of the other variables are fixed. In the last column of Table 3, the "S" and "F" represent the strength (compressive and flexural) test and flexural toughness test, respectively.

\subsection{Specimen preparation}

Firstly, the magnesium oxide, potassium dihydrogen phosphate, borax and sand were mixed evenly by a concrete mixer with single horizontal shaft at a low speed. The capacity of the mixer was $20 \mathrm{~L}$. Secondly, the MSF were slowly added into the mixture. Finally, the water was added slowly into the mixer for $30 \mathrm{sec}$, followed by a rapid mixing for $60 \mathrm{sec}$. The mixture was cast into the steel moulds of 
$40 \mathrm{~mm} \times 40 \mathrm{~mm} \times 160 \mathrm{~mm}$ and $100 \mathrm{~mm} \times 100 \mathrm{~mm} \times 400 \mathrm{~mm}$ for the strength and flexural toughness tests, respectively. Next, the steel moulds were compacted on a vibration table. The specimens prepared with MPPC, SAC and OPC were demolded after 1 hour, 2 hours and 12 hours, respectively, and cured in the standard curing room with a $95 \%$ relative humidity and $20^{\circ} \mathrm{C}$ temperature. The mixing process and prepared specimens for flexural toughness test are shown in Figure 2 and Figure 3, respectively.

The specimens prepared with MPPC for the compressive strength and flexural strength were cured for 6 hours, 12 hours, 1 day, 3 days and 7 days. The specimens prepared with SAC and OPC for the compressive strength were cured just for 7 days. The specimens of Group M-F-1.2\% for the test of flexural toughness were cured for 1 day, 3 days and 7 days; all the other specimens for the test of flexural toughness were cured just for 7 days. Three specimens from each group were tested for the strength and toughness according to GB/T17671-1999 [45] and ASTM C1609 [46], respectively. In this study, there are totally 195 specimens of $40 \mathrm{~mm} \times 40 \mathrm{~mm} \times 160 \mathrm{~mm}$ and 54 specimens of 100 $\mathrm{mm} \times 100 \mathrm{~mm} \times 400 \mathrm{~mm}$ for the strength test and toughness test, respectively.

\subsection{Workability of the mixtures}

The workability of the fresh concrete is usually measured by slump tests $[47,48]$. The slumps of the mixtures were measured according to ASTM C143/C143M-15a [48] using a steel mold, as shown in Figure 4. After mixing the ingredients (Section 2.3), the mixtures were filled fully in the mold which was placed on a rigid, flat, level and moist surface. Then, the mold was steadily lifted to about 300 mm. As shown in Figure 4, the slumps were measured by the vertical difference between the top of the mold and the displaced centre of the top surface of the mixture.

\subsection{Compressive and flexural strength tests}

The compressive strength and flexural strength tests were conducted according to GB/T17671-1999 [45]. A universal testing machine with a capacity of $300 \mathrm{kN}$ was used for the compressive strength 
and flexural strength tests, as shown in Figure 4. At first, the $40 \mathrm{~mm} \times 40 \mathrm{~mm} \times 160 \mathrm{~mm}$ prism specimens with a span length of $100 \mathrm{~mm}$ were loaded in the middle until fracture to measure the flexural strength (Figure 5a). The loading rate was $50 \mathrm{~N} / \mathrm{s}$. Afterwards, the two parts of each fractured prism specimen were placed on the compressive strength test setup with a compression area of 40 $\mathrm{mm} \times 40 \mathrm{~mm}$ (Figure 5b) to test the compressive strength at a loading rate of $2.4 \mathrm{kN} / \mathrm{s}$. The flexural strength $\left(f_{\mathrm{f}}\right)$ was calculated by Eq. (1) and the compressive strength $\left(f_{\mathrm{c}}^{\prime}\right)$ was calculated by Eq. (2).

$$
\begin{gathered}
f_{\mathrm{f}}=\frac{1.5 P \times L}{b^{3}} \\
f_{\mathrm{c}}^{\prime}=\frac{P}{A}
\end{gathered}
$$

where $P$ is the maximum load; $A$ is the area under compression $\left(A=1600 \mathrm{~mm}^{2}\right.$ for this test); $b$ is the side length of the square cross-section of the prism specimen ( $b=40 \mathrm{~mm}$ for this test); $L$ is the span length ( $L=100 \mathrm{~mm}$ for this test).

\subsection{Flexural toughness test}

The $100 \mathrm{~mm} \times 100 \mathrm{~mm} \times 400 \mathrm{~mm}$ prism specimens were tested for flexural toughness according to ASTM C1609 [46], as shown in Figure 6. The test was conducted by using a universal testing machine with a capacity of $500 \mathrm{kN}$. The third-point loading was applied on the prism specimen at the rate of increase of net deflection of $0.1 \mathrm{~mm} / \mathrm{min}$. To achieve accurate net deflection at the midspan excluding the effects of seating or twisting of the specimen on its supports, a rectangular jig was used around the specimen. The jig was clamped to the specimen at the mid-depth directly over the supports. Two linear variable displacement transducers (LVDTs) were mounted on the jig at midspan (one on each side) to measure the midspan deflection (Figure 6). The average of the two measurements represented the midspan deflection. The applied load was recorded by a load transducer with a capacity of $100 \mathrm{kN}$. All the readings (load and deflection) were collected by a data logger every two seconds. 
The ASTM C1609 [39] defines the total area under the flexural load-midspan deflection curve up to $L / 150$ ( $L$ is beam span, $L=300 \mathrm{~mm}$ for this test) as flexural toughness, $T_{150}^{D}(\mathrm{~N} \cdot \mathrm{mm})$. The equivalent flexural strength ratio, $R_{T, 150}^{D}$, can be calculated by Eq. (4):

$$
R_{T, 150}^{D}=\frac{150 T_{150}^{D}}{f_{1} b h^{2}} \times 100 \%
$$

where $f_{1}$ is the first peak strength (MPa); $b$ is the width of the specimen ( $b=100 \mathrm{~mm}$ for this test); and $h$ is the height of the specimen ( $h=100 \mathrm{~mm}$ for this test). The flexural toughness, $T_{150}^{D}$, reflects the energy absorption capacity of MSF reinforced composites. The equivalent flexural strength ratio, $R_{T, 150}^{D}$, reflects the flexural ductility of MSF reinforced composites determined by the plump degree (fat or thin) of flexural load-midspan deflection curves.

\section{Results and discussion}

Test results of the compressive strength and flexural strength of MSF reinforced MPPC composite are shown in Table 4. The average compressive strengths of SAC and OPC composites with the addition of different proportions of MSF by volume for 7-day curing are shown in Table 5 and Table 6 , respectively. The slumps of the mixtures prepared with MPPC, SAC and OPC are summarized in Table 4, Table 5 and Table 6, respectively. The flexural toughness, $T_{150}^{D}$, and the equivalent flexural strength ratio, $R_{T, 150}^{D}$, calculated by Eq. (3) for the tested specimens are shown in Table 7.

\subsection{Workability of the mixtures}

Figure 7 presents the slumps of the mixtures prepared with MPPC. The "S/C" and "W/C" represented sand-cement mass ratio and water-cement mass ratio, respectively. Figure 8 presents the slump of the mixtures prepared with SAC and OPC. The proportions of the various mixtures are listed in the Table 3. As shown in the Figure 7, the slumps of the mixtures prepared with MPPC increased from $32 \mathrm{~mm}$ to $45 \mathrm{~mm}$ with the decrease of the sand-cement mass ratio from 1.2 to 0.8 and increased from $28 \mathrm{~mm}$ 
to $52 \mathrm{~mm}$ with the increase of water-cement mass ratio from 0.16 to 0.20 . Also, the slumps of the mixtures prepared with MPPC decreased from $57 \mathrm{~mm}$ to $24 \mathrm{~mm}$ with the increase of the volume fraction of MSF from $0.0 \%$ to $1.6 \%$. As shown in Figure 8, the slumps of the mixtures prepared with SAC and OPC decreased significantly with the increase of the volume fraction of MSF from $0.0 \%$ to $1.6 \%$. The slumps of the mixtures prepared with MPPC were slightly greater than the slumps of the mixtures prepared with SAC. However, the slumps of the mixtures prepared with MPPC and SAC were significantly lower than the slumps of the mixtures prepared with OPC.

\subsection{Effect of sand-cement mass ratio on the mechanical properties of MSFRMC}

Figure 9 shows the effect of sand-cement mass ratio on the average compressive and flexural strength of MSFRMC at the curing time of 6 hours, 12 hours, 1 day, 3 days and 7 days. It can be observed that the average compressive and flexural strengths significantly increased with the increase of the curing time, especially up to 3 days. The average compressive strengths of specimens with sand-cement mass ratio of 0.8 (Specimens M-S/C-0.8), 1.0 (Specimens M-S/C-1.0) and 1.2 (Specimens M-S/C-1.2) at curing time of 3 days developed by about $93.6 \%, 88.1 \%$ and $98.7 \%$, respectively, of the average compressive strength at 7 days. The average flexural strengths of specimens with sand-cement mass ratio of 0.8 (Specimens M-S/C-0.8), 1.0 (Specimens M-S/C-1.0) and 1.2 (Specimens M-S/C-1.2) at curing time of 3 days developed by about $71.0 \%, 89.0 \%$ and $81.6 \%$, respectively, of the average flexural strength at 7 days. In this experiment, the water-cement mass ratio was kept constant but the sand-cement mass ratio was changed. The amount of cement and also the amount of water in specimens of Group M-S/C-0.8 were the largest. Chen [8] reported that larger water content created more pores inside the MPPC matrix. Therefore, it was expected that the specimens of Group M-S/C0.8 would contain the highest amount of pores. The compressive and flexural strength of Group MS/C-0.8 were lower than those of Group M-S/C-1.0 up to 1 day of curing due to the presence of more pores in Group M-S/C-0.8 specimens. With the further hydration process of MPPC, as the amount of cement in the paste of Group M-S/C-0.8 was more than the amount of cement in the paste of Group M-S/C-1.0, the hydration products in specimens of Group M-S/C-0.8 increased more rapidly than the hydration products in specimens of Group M-S/C-1.0. From 1 day to 3 days of curing, the increase of 
271 the compressive strengths of Group M-S/C-0.8 was significantly more than that of Group M-S/C-1.0.

272 From 3 days to 7 days of curing, the increase of the flexural strength of Group M-S/C-0.8 was

273 significantly more than that of Group M-S/C-1.0. The compressive and flexural strength of Group M-

274 S/C-0.8 and Group M-S/C-1.0 specimens were similar at 7 days of curing. Group M-S/C-1.0

275 specimens had the largest average compressive and flexural strengths at all curing time. However, the excess sand caused the poor workability of the MSFRMC mixtures as shown in Figure 7. The poor workability introduced more pores inside the MSFRMC specimens. Also, the amount of cement gradually decreased with the increase of the sand-cement mass ratio, which resulted in the decrease of the cementitious hydration products. These factors were responsible for the lower compressive and flexural strengths of specimens of Group M-S/C-1.2 than the compressive and flexural strengths of specimens of Group M-S/C-1.0.

282

Figure 10 shows the effect of sand-cement mass ratio on the flexural load-midspan deflection behaviour of MSFRMC specimens. With the increase of sand-cement mass ratio from 0.8 to 1.2 , the cement content in the mixtures decreased and the peak flexural load decreased. The decrease is especially significant for sand-cement mass ratio of 1.2. The effect of sand-cement mass ratio on flexural toughness, $T_{150}^{D}$, and equivalent flexural strength ratio, $R_{T, 150}^{D}$, of MSFRMC specimens are presented in Figure 11. With the increase of sand-cement mass ratio from 0.8 to 1.2 , the $T_{150}^{D}$ and $R_{T, 150}^{D}$ decreased by $17.39 \%$ and $9.88 \%$, respectively. This indicated a moderate reduction in the flexural toughness and ductility of MSFRMC with the increase of sand-cement mass ratio. As the cementitious hydration products decreased and the pores inside the specimens increased with the increase of sand-cement mass ratio, the flexural toughness and ductility of MSFRMC decreased.

\subsection{Effect of water-cement mass ratio on the mechanical properties of MSFRMC}

Figure 12 shows the effect of water-cement mass ratio on average compressive and flexural strengths of MSFRMC at the curing time of 6 hours, 12 hours, 1 day, 3 days and 7 days. Fast development of 
the compressive and flexural strengths could be observed up to 3 days of curing. The average compressive strength of specimens with water-cement mass ratio of 0.16 (Specimens M-W/C-0.16), 0.18 (Specimens M-W/C-0.18) and 0.20 (Specimens M-W/C-0.20) at 3 days of curing developed by about $88.2 \%, 88.1 \%$ and $89.7 \%$, respectively, of the average compressive strength of specimens at 7 days of curing. The average flexural strength of specimens with water-cement mass ratio of 0.16 (Specimens M-W/C-0.16), 0.18 (Specimens M-W/C-0.18) and 0.20 (Specimens M-W/C-0.20) at 3 days of curing developed by about $89.1 \%, 89.0 \%$ and $80.3 \%$, respectively, of the average flexural strength of specimens at 7 days of curing. Group M-W/C-0.16 specimens showed the highest compressive and flexural strengths compared to the other specimens at all curing time. With the increase of water-cement mass ratio from 0.16 to 0.20 , the average compressive and flexural strengths decreased. The large content of the water in the pastes was useful for improving the workability of the mixture, as presented in Section 3.1. However, the excess water increased the porosity of the MPPC specimens (Section 3.2) and resulted in the lower compressive and flexural strength.

Figure 13 shows the effect of water-cement mass ratio on the flexural load-midspan deflection behaviour of MSFRMC specimens. With the increase of water-cement mass ratio from 0.16 to 0.20 , the water content in the mixtures increased. The increase of water content resulted in the decrease of peak flexural load. The effect of water-cement mass ratio on flexural toughness, $T_{150}^{D}$, and equivalent flexural strength ratio, $R_{T, 150}^{D}$, of MSFRMC specimens are presented in Figure 14. With the increase in the water-cement mass ratio from 0.16 to 0.20 , the flexural toughness, $T_{150}^{D}$, decreased by $12.5 \%$. This indicated that the flexural toughness of MSFRMC decreased significantly with the increase of water content in the paste. The significant decrease of the flexural toughness of MSFRMC can be attributed to the presence of more pores inside the MPC specimens due to the increase of water content. However the equivalent flexural strength ratio, $R_{T, 150}^{D}$, increased by $7.6 \%$. The increment of $R_{T, 150}^{D}$ indicated the slight increase of the flexural ductility of MSFRMC with the increase of water content. The increase of water content in specimens decreased the compressive strength of MSFRMC. 
323 However, the increase of water content in specimens reduced the brittleness of the composites and 324 increased the flexural ductility of MSFRMC.

\subsection{Effect of MSF on the mechanical properties of MSFRMC}

327

Figure 15 shows the effect of the addition of MSF by volume on the average compressive and flexural strength of MSFRMC at the curing time of 6 hours, 12 hours, 1 day, 3 days and 7 days. It can be seen that the average compressive and flexural strength noticeably increased with the increase of curing time. The high early compressive and flexural strengths of MSFRMC were obvious due to the fast hydration of MPPC, as reported in Ding [9]. The average compressive strength of specimens with fibre volume fraction of $0.0 \%$ (Specimens M-F-0.0\%), $0.4 \%$ (Specimens M-F-0.4\%), $0.8 \%$ (Specimens M-F-0.8\%), 1.2\% (Specimens M-F-1.2\%) and 1.6\% (Specimens M-F-1.6\%) at 3 days of curing developed by about $90.0 \%, 84.8 \%, 90.7 \%, 88.1 \%$ and $90.4 \%$, respectively, of the average compressive strength of specimens at 7 days of curing. The average flexural strength of specimens with fibre volume fraction of $0.0 \%$ (Specimens M-F-0.0\%), 0.4\% (Specimens M-F-0.4\%), 0.8\% (Specimens M-F-0.8\%), 1.2\% (Specimens M-F-1.2\%) and 1.6\% (Specimens M-F-1.6\%) at 3 days of curing developed by about $79.7 \%, 90.2 \%, 97.6 \%, 89.0 \%$ and $86.6 \%$, respectively, of the average flexural strength of specimens at 7 days of curing. With the increase of the addition of MSF, the compressive and flexural strengths of the specimens of MSFRMC improved significantly at all curing time. Compared to the specimens without MSF, the average compressive strength of the specimens with the addition of $1.6 \%$ MSF by volume cured for 6 hours, 12 hours, 1 day, 3 days and 7 days increased by about $95.7 \%, 106.9 \%, 62.2 \%, 61.3 \%$ and $53.6 \%$, respectively. The average flexural strength of the specimens with the addition of $1.6 \%$ MSF by volume cured for 6 hours, 12 hours, 1 day, 3 days and 7 days increased by about 216.7\%, 200.0\%, 162.3\%, $147.6 \%$ and $135.0 \%$, respectively. It is noted that the addition of MSF in the improvement of the flexural strength was higher than the improvement of the compressive strength of MPPC composite. 
Figure 16 presents the effect of the addition of MSF on flexural load versus midspan deflection of specimens cured for 7 days. All the specimens with MSF showed a ductile failure with the descending post-peak behaviour, representing a ductile response after the peak load. With the increase of the addition of MSF from $0.8 \%$ to $1.6 \%$ by volume, the flexural peak load increased gradually. The residual midspan deflection of post peak-load also increased. The effect of adding of MSF on flexural toughness, $T_{150}^{D}$, and equivalent flexural strength ratio, $R_{T, 150}^{D}$, of the MSFRMC specimens are shown in Figure 17. With the increase of the addition of MSF from $0.8 \%$ to $1.6 \%$ by volume, the flexural toughness, $T_{150}^{D}$, and the equivalent flexural strength ratio, $R_{T, 150}^{D}$, of the specimens increased reflected the flexural ductility of fibre reinforced composites. The flexural ductility of MSFRMC increased significantly with the increase of the addition of MSF. The addition of MSF prominently contributed to the development of the flexural toughness and ductility of MSFRMC. It is noted that the improvement for the addition of MSF on the flexural toughness was higher than the improvement for the addition of MSF on the flexural ductility of MSFRMC. strength, flexural strength and flexural toughness of MSFRMC.

3.5 Effect of different types of cement on the mechanical properties of MSF reinforced composites

Figure 18 presents the effect of different types of cement on the average compressive strength of 

specimens of MSF reinforced composites for the addition of various volume fractions of MSF at 7 days of curing. The sand-cement mass ratio of MPPC, SAC and OPC based composites was 1.0. As shown in Figure 18, the average compressive strength of composites prepared by SAC and OPC increased gradually with the increase of the volume fraction of MSF from $0.0 \%$ to $1.6 \%$. The average compressive strength of composites prepared by MPPC increased significantly with the increase of the volume fraction of MSF up to $1.2 \%$. With the increase of the volume fraction of MSF from $1.2 \%$ to $1.6 \%$, the average compressive strength of composite prepared by MPPC decreased slightly. It indicated that the optimal addition of MSF for improving the compressive strength of MPPC based composite was lower than the optimum addition of MSF for improving the compressive strength of OPC based and SAC based composites. Although the average compressive strength of MPPC based composites without the addition of MSF was significantly lower, the average compressive strength of MPPC, SAC and OPC based composites for the addition of $1.6 \%$ MSF by volume was similar. The average compressive strength of the specimens of MPPC, SAC and OPC based composites with the MSF volume fraction of $1.6 \%$ increased by about $69.8 \%, 32.3 \%$ and $24.8 \%$, respectively, compared to the average compressive strength of the specimens without MSF. It can be observed that the addition of MSF exhibited the most effective improvement of the compressive strength on MPPC composite.

Figure 19 and Figure 20 present the flexural load-midspan deflection curves of SAC-based and OPCbased composites, respectively, cured for 7 days with the addition of various volume fraction of MSF. With the increase of the addition of MSF from $0.8 \%$ to $1.6 \%$ by volume, the peak load and fullness of the flexural load-midspan deflection curves improved significantly. However, the flexural loadmidspan deflection curves of SAC-based and OPC-based composites were lower than the flexural load-midspan deflection curves of MPPC-based composite reinforced with MSF of $1.6 \%$ by volume.

Figure 21 and Figure 22 present the effect of cement type on flexural toughness, $T_{150}^{D}$, and equivalent flexural strength ratio, $R_{T, 150}^{D}$, respectively, of the composites prepared with MPPC, SAC and OPC, with varying volume fraction of MSF. With the increase of the addition of $0.8 \%$ to $1.6 \%$ MSF by volume, the flexural toughness, $T_{150}^{D}$, of the composites prepared with MPPC, SAC and OPC 
improved by $104.5 \%, 52.5 \%$ and $38.4 \%$, respectively. The improvement of the flexural toughness of MPPC-based composite was the most significant. Compared to SAC and OPC, the flexural toughness, $T_{150}^{D}$, of the MPPC-based composites with the volume fraction of MSF of $1.6 \%$ was the largest. With the increase of the addition of MSF from $0.8 \%$ to $1.6 \%$ by volume, the equivalent flexural strength ratio, $R_{T, 150}^{D}$, of the composites with MPPC, SAC and OPC increased by $54.3 \%, 13.2 \%$ and $8.6 \%$, respectively. The improvement of the flexural ductility of MPPC based composite was the most significant.

The effect of MSF on the improvement of the compressive strength, flexural toughness and ductility for MPPC-based composites was the most significant compared to the improvement of those for SAC-based and OPC-based composites. The significant improvement of compressive strength, flexural toughness and ductility of MPPC-based composites was due to the developed bond properties between MSF and MPPC matrix [50].

\subsection{Effect of curing time on flexural toughness and ductility}

Figure 23 presents the effect of curing time on the flexural load versus midspan deflection of specimens of Group M-F-1.2\%. With the increase of the curing time from 1 day to 7 days, the peak load of the flexural load-midspan deflection curves increased.

The effect of curing time on flexural toughness, $T_{150}^{D}$, and equivalent flexural strength ratio, $R_{T, 150}^{D}$, of the MSFRMC specimens are shown in Figure 24. It can be observed that the flexural toughness, $T_{150}^{D}$, of the specimens clearly increased with the increase of curing time. The flexural toughness, $T_{150}^{D}$, of specimens cured for 1 day and 3 days developed by $82.7 \%$ and $92.7 \%$, respectively, of the flexural toughness, $T_{150}^{D}$, of specimens cured for 7 days. Also, the equivalent flexural strength ratio, $R_{T, 150}^{D}$, of the specimens increased during the first 3 days of curing. The equivalent flexural strength ratio, $R_{T, 150}^{D}$, of the specimens for 3 days and 7 days were similar. It is evident that the rate of increase of the 
flexural ductility was higher than the rate of increase of the flexural toughness of MSFRMC for the 7 day curing period. It can be observed that the flexural toughness and ductility of MSFRMC were developed significantly during 1 day curing. The high flexural toughness and ductility during 1 day curing were due to the fast hydration of MPPC [9].

\section{Conclusions}

The mechanical properties of micro-steel fibre (MSF) reinforced MPPC composite (MSFRMC) were experimentally investigated. The effects of the variables including mixture design parameters, fibre volume fraction, curing time and types of cement on the strength, flexural toughness and ductility of MSF reinforced composites were explored. The following conclusions can be drawn:

1) With the increase of water-cement mass ratio from 0.16 to 0.20 , the average compressive strength, flexural strength and flexural toughness of MSFRMC decreased significantly. However the ductility of MSFRMC increased slightly. The excess water increased and resulted in the lower compressive strength, flexural strength and flexural toughness. However, the increase of water content slightly reduced the brittleness of the matrix.

2) For the increase of the sand-cement mass ratio from 0.8 to 1.2, the flexural toughness of MSFRMC decreased significantly, although the flexural ductility of MSFRMC decreased moderately. Sufficient amount of MPPC in the mixture is necessary to improve the toughness and ductility of MSFRMC.

3) For the increase of the addition of MSF by volume, the compressive strength, flexural strength, flexural toughness and flexural ductility of MSFRMC improved significantly. The increase of the flexural strength was higher than the increase of the compressive strength. The improvement of the flexural toughness was more than the improvement of the flexural ductility. 
455 4) The compressive strength, flexural strength, flexural toughness and flexural ductility of MSFRMC 456 were very high at early curing time, especially up to 3 days. This was due to the fast hydration of 457 MPPC.

458

459 5) In comparison to the SAC and OPC based composites, the addition of MSF in MPPC based 460 composites improved the compressive strength, flexural toughness and flexural ductility more 461 significantly. The reinforcing effect of MSF on the MPPC based composite is greater than the 462 reinforcing effect of MSF on the SAC and OPC based composites.

463

464 This study demonstrated, though experimental investigations, the potential of the incorporation of 465 MSF in improving the strength, toughness and ductility of MPPC based composites. It was also 466 demonstrated that MSFRMC with various mechanical properties and workability could be prepared. It 467 is noted that the slump of fresh MSFRMC was lower than the slump of the OPC based composites. 468 The improvement in the workability of the MSFRMC is necessary for its wide application and is 469 considered part of the ongoing research studies by the authors. 


\section{Acknowledgments}

472 The first author would like to acknowledge the University of Wollongong, Australia, and the China

473 Scholarship Council for supporting his overseas research scholarship. All the authors acknowledge the

474 University of Wollongong, Australia for providing research foundation. Financial support from

475 National Natural Science Foundation of China (Grant No. 51308504) and Scientific \& Technological

476 Project of Henan Province (152102310068) are gratefully acknowledged. 


\section{References}

478 [1] M. Kouassi, P. Michailesco, A. Lacoste-Armynot, P. Boudeville, Antibacterial effect of a 479 hydraulic calcium phosphate cement for dental applications, Journal of Endodontics, 29 (2) (2003) $480 \quad 100-103$.

481 [2] F. Wu, J. Wei, H. Guo, F. Chen, H. Hong, C. Liu, Self-setting bioactive calcium-magnesium 482 phosphate cement with high strength and degradability for bone regeneration, Acta Biomaterialia, 4 (6) 483 (2008) 1873-1884.

484 [3] G. Mestres, MP. Ginebra, Novel magnesium phosphate cements with high early strength and 485 antibacterial properties, Acta Biomaterialia, 7 (4) (2011) 1853-1861.

486 [4] J. Yunsong, A new type of light magnesium cement foamed material, Mater Lett, 56 (3) (2002) $487353-356$.

488 [5] Z. Ding, B. Dong, F. Xing, Magnesium phosphate cement with large volume of fly ash, Applied 489 Mechanics \& Materials , 174-177 (2012) 802-805.

490 [6] J. Torras, I. Buj, M. Rovira, J. de Pablo, Semi-dynamic leaching tests of nickel containing wastes 491 stabilized/solidified with magnesium potassium phosphate cements, J Hazard Mater, 186 (2-3) (2011) 492 1954-1960.

493 [7] S. Iyengar, A. Al-Tabbaa, Application of two novel magnesia-based cements in the 494 stabilization/solidification of contaminated soils, GeoCongress, 177 (2008) 716-723.

495 [8] Y. Li, B. Chen, Factors that affect the properties of magnesium phosphate cement, Constr. Build. 496 Mater. 47 (2013) 977-983

497 [9] Q. B. Yang, S. Q. Zhang, X. L. Wu, Deicer-scaling resistance of phosphate cement-based binder 498 for rapid repair of concrete, Cem. Concr. Res. 32 (1) (2002) 165-168

499 [10] Q. Yang, B. Zhu, X. Wu, Characteristics and durability test of magnesium phosphate cement500 based material for rapid repair of concrete, Mater. Struct. 33 (4) (228) (2000) 229-234

501 [11] S. S. Seehra Ms., Saroj Gupta, Satander Kumar, Rapid setting magnesium phosphate cement for 502 quick repair of concrete pavements-characterisation and durability aspects, Cem. Concr. Res. 23 (2) 503 (1993) 254-266

504 [12] T. Sugama, L. E. Kukacka, Magnesium monophosphate cements derived from diammonium 505 phosphate solutions, Cem. Concr. Res. 13 (3) (1983) 407-416

506 [13] A. K. Sarkar, Hydration/dehydration characteristics of struvite and dittmarite pertaining to 507 magnesium ammonium phosphate cement system, J. Mater. Sci. 26 (9) (1991) 2514-2518

508 [14] B. E. I. Abdelrazig, J. H. Sharp, B. EI-Jazairi, The chemical composition of mortars made from 509 magnesia-phosphate cement, Cem. Concr. Res. 18 (3) (1998) 415-425

510 [15] Q. B. Yang, X. L. Wu, Factors influencing properties of phosphate cement based binder for rapid 511 repair of concrete, Cem. Concr. Res. 29 (4) (1999) 389-396

512 [16] Z. Ding, Z. J. Li, High-early-strength magnesium phosphate cement with fly ash, ACI J. Mater. 
514 [17] Z. Ding, Z. J. Li, Effect of aggregates and water contents on the properties of magnesium 515 phospho-silicate cement, Cem. Concr. Compos. 27 (1) (2005) 11-18

516 [18] E. Soudée, J. Péra, Mechanism of setting reaction in magnesia-phosphate cements, Cem. Concr. 517 Res. 30 (2) (2000) 315-321

518 [19] F. Qiao, C. K. Chau, Z. J. Li, Property evaluation of magnesium phosphate cement mortar as 519 patch repair material, Constr. Build. Mater. 24(5) (2010) 695-700

520 [20] D. A. Hall, R. Stevens, B. El-Jazairi, The effect of retarders on the microstructure and 521 mechanical properties of magnesia-phosphate cement mortar, Cem. Concr. Res. 31 (3) (2001) 455$522 \quad 465$

523 [21] C. K. Chau, F. Qiao, Z. J. Li, Microstructure of magnesium potassium phosphate cement, Constr. 524 Build. Mater. 25 (6) (2011) 2911-2917

525 [22] F. Qiao, C. K. Chau, Z. J. Li, Setting and compressive strength characteristics of magnesium 526 phosphate cement paste, Adv. Cem. Res. 21 (4) (2009) 175-180

527 [23] J. Yang, C. Qian, Effect of borax on hydration and hardening properties of magnesium and 528 potassium phosphate cement pastes, Journal of Wuhan University of Technology-Materials and 529 Science Edition, 25 (4) (2010) 613-618

530 [24] S. J. Fan, B. Chen, Experimental study of phosphate salts influencing properties of magnesium 531 phosphate cement, Constr. Build. Mater. 65 (2014) 480-486

532 [25] J. Yang, C. Qian, B. Jiao, Effect of $\mathrm{NaH}_{2} \mathrm{PO}_{4} \cdot 12 \mathrm{H}_{2} \mathrm{O}$ on Hydration and Hardening Properties of 533 Potassium and Magnesium Phosphate Cement Paste, Journal of Building Materials, 14 (3) (2011) 534 300-305 (In Chinese)

535 [26] X. Duan, S. Lv, Preparation of a Multi-composite Retarder and Its Effect on Properties of 536 Magnesium Phosphate Cement, Journal of Wuhan University of Technology, 36 (10) (2014) 20-25 (In 537 Chinese)

538 [27] A. Ezeldin, P. Balaguru, Toughness behavior of fiber reinforced rapid set materials: A 539 Preliminary Study, ASTM Journal, Cement, Concrete, and Aggregates, 14 (1) (1992) 3-7

540 [28] A. Bhutta, P.H.R. Borges, C. Zanotti, M. Farooq, N. Banthia, Flexural behavior of geopolymer 541 composites reinforced with steel and polypropylene macro fibers, Cem. Concr. Compos. 80 (2017) $542 \quad 31-40$

543 [29] P. Frantzis, R. Baggott, Transition points in steel fiber pullout tests from magnesium phosphate 544 and accelerated calcium aluminates binders, Cem. Concr. Compos. 25 (1) (2003) 11-17

545 [30] P. Frantzis, R. Baggott, Bond between reinforcing steel fibres and magnesium phosphate/calcium 546 aluminate binders, Cem. Concr. Compos. 22 (3) (2000) 187-192

547 [31] H. Wang, J. Qian, J. Cao, B. Shen, Properties and Application of Steel-Fiber Reinforced 548 Magnesia Phosphate Cement Mortar, J. Architectural Technology, 37 (6) (2006) 462-464 (In Chinese) 549 [32] J. Péra, J. Ambroise, Fiber-reinforced Magnesia-phosphate Cement Composites for Rapid Repair, 
Cem. Concr. Compos. 20 (1) (1998) 31-39

[33] P. Richard, M. Cheyrezy, Composition of reactive powder concretes, Cem. Concr. Res. 25 (7) (1995) 1501-1511

[34] A. Cwirzen, V. Penttala, C. Vornanen, Reactive powder based concretes: Mechanical properties, durability and hybrid use with OPC, Cem. Concr. Res. 38 (10) (2008) 1217-1226 [35] CS (Chinese Standard) GB/T 31387-2015, Reactive Powder Concretes (in Chinese). [36] Zhengyang Casting Material Company. Xinmi, Henan, China. http://www.igreenbuy.com/index.php/shop-info-2728.html/ (Accessed on December 2017) (in Chinese)

[37] Weitong Chemical Co., Ltd of Wujiang, Jiangsu, China. https://wjwthg1818.1688.com/ (Accessed on December 2017) (in Chinese)

[38] Banda Technology Co., Ltd. of Liaoning, China. http://www.lnpdkj.com/ (Accessed on December 2017) (in Chinese)

[39] Kermel Chemical Reagent Co., Ltd. Tianjin, China. http://www.tjkermel.com/ (Accessed on December 2017) (in Chinese)

[40] Shanghai Realstrong Steel Fibre Co., Ltd. 365 Wang Ln, Jinze Town, Shanghai, China. http://www.realstrong.cn/cn/product151.asp (Accessed on December 2017)

[41] CS (Chinese Standard) GB20472-2006, Sulphoaluminate Cement (in Chinese). [42] CS (Chinese Standard) GB175-2007, Common Portland Cement (in Chinese).

[43] Yicheng Anda Special Cement Co., Ltd. Group. Banqiaodian Town, Yicheng, Hubei, China. http://www.hbadtzsn.com/yewu/36.html/ (Accessed on December 2017) (in Chinese)

[44] Mengdian Group Cement Co., Ltd. Huixian, Henan, China. http://www.hnmdjt.com/(Accessed on December 2017) (in Chinese)

[45] CS (Chinese Standard) GB/T 17671-1999, Cement mortar strength testing method (ISO) (in Chinese).

[46] ASTM C1609/C1609M-12, Standard Test Method for Flexural Performance of Fiber-Reinforced Concrete (Using Beam with Third-Point Loading), ASTM International, West Conshohocken, PA, 2012, www.astm.org.

[47] CS (Chinese Standard) GB/T50080-2016, Standard for test method of performance on ordinary fresh concrete, Ministry of Housing and Urban-Rural Development People's Republic China, 2016 (in Chinese).

[48] ASTM C143/C143M-15a, Standard Test Method for Slump of Hydraulic-Cement Concrete, ASTM International, West Conshohocken, PA, 2015, www.astm.org.

[49] D. Gao, J. Liu, Fundamental Theory of Steel Fibre Reinforced Concrete, Scientific and Technical Documentation Press, 1994 (in Chinese).

[50] Lu Feng, Study on Bonding Performance of the Interface between Steel Fibre and Magnesium Phosphate Cement Matrix, Master Thesis of Zhengzhou University, 2018. 
588 Table 1 Oxide composition of $\mathrm{MgO}[36]$

589 Table 2 Properties of micro steel fibres [40]

590 Table 3 Mix proportions of MSF reinforced composites

591 Table 4 Slump, average compressive strength and flexural strength of MSFRMC

592 Table 5 Slump and average compressive strength of SAC composite with varying volume fractions of 593 MSF

594 Table 6 Slump and average compressive strength of OPC composite with varying volume fractions of $595 \mathrm{MSF}$

596 Table 7 Flexural toughness and ductility index of MSF reinforced composites

597 
599 Figure 1 Micro-steel fibres

600 Figure 2 Mixing process of MSFRMC mixture

601 Figure 3 Specimens of MSFRMC for flexural toughness test

602 Figure 4 Slumps measuring: (a) Schematic representation of slump measuring and (b) Photo of slump 603 measuring

604 Figure 5 Flexural and Compressive strength test: (a) Schematic representation of flexural strength test,

605 (b) Schematic representation of compressive strength test and (c) Photo of the test

606 Figure 6 Flexural toughness test: (a) Schematic representation and (b) Photo of the test

607 Figure 7 Slumps of the mixtures prepared with MPPC

608 Figure 8 Slumps of the mixtures prepared with SAC and OPC with varying volume fraction of MSF

609 Figure 9 Effect of sand-cement mass ratio on: (a) average compressive strength and (b) average

610 flexural strength

611 Figure 10 Effect of sand-cement mass ratio on flexural load versus midspan deflection of MSFRMC

612 cured for 7 days

613 Figure 11 Effect of sand-cement mass ratio on flexural toughness and ductility of MSFRMC cured for 6147 days

615 Figure 12 Effect of water-cement mass ratio on: (a) average compressive strength and (b) average 616 flexural strength

617 Figure 13 Effect of water-cement mass ratio on flexural load versus midspan deflection of MSFRMC 618 cured for 7 days

619 Figure 14 Effect of water-cement mass ratio on flexural toughness and ductility of MSFRMC cured 620 for 7 days

621 Figure 15 Effect of volume fraction of MSF on: (a) average compressive strength and (b) average

622 flexural strength

623 Figure 16 Effect of volume fraction of MSF on flexural load versus midspan deflection of MSFRMC 624 cured for 7 days

625 Figure 17 Effect of volume fraction of MSF on flexural toughness and ductility of MSFRMC cured 626 for 7 days

627 Figure 18 Effect of volume fraction of MSF on the average compressive strength for MPPC-based,

628 SAC-based and OPC-based composites cured for 7 days

629 Figure 19 Effect of volume fraction of MSF on flexural load versus midspan deflection of SAC based 630 composites cured for 7 days

631 Figure 20 Effect of volume fraction of MSF on flexural load versus midspan deflection of OPC based 632 composites cured for 7 days

633 Figure 21 Flexural toughness of different cements based composites with varying volume fraction of 634 MSF cured for 7days

635 Figure 22 Flexural ductility of different cements based composites with varying volume fraction of 636 MSF cured for 7days

637 Figure 23 Effect of curing time on flexural load versus midspan deflection of MSFRMC with 1.2\%

638 MSF by volume (Group M-F-1.2\%)

639 Figure 24 Effect of curing time on flexural toughness and ductility of MSFRMC with $1.2 \%$ MSF by 640 volume (Group M-F-1.2\%) 
641 Table 1

642 Oxide composition of $\mathrm{MgO}$ [36]

\begin{tabular}{cccccc}
\hline Composition & $\mathrm{MgO}$ & $\mathrm{Fe}_{2} \mathrm{O}_{3}$ & $\mathrm{SiO}_{2}$ & $\mathrm{CaO}$ & Others \\
\hline $\begin{array}{c}\text { Mass fraction of } \\
\text { the sample (\%) }\end{array}$ & 92.53 & 0.87 & 3.1 & 1.6 & 1.9 \\
\hline
\end{tabular}

643

644 
645 Table 2

646 Properties of micro steel fibres [40]

\begin{tabular}{ccccc}
\hline Type & Length, $L(\mathrm{~mm})$ & Diameter, $D(\mathrm{~mm})$ & $\begin{array}{c}\text { Tensile strength } \\
(\mathrm{MPa})\end{array}$ & $\begin{array}{c}\text { Number per } \\
\text { kilogram }\end{array}$ \\
\hline RS60/13-2850 & 13 & 0.22 & 2850 & 224862 \\
\hline
\end{tabular}

647 
649 Mixture proportions of MSF reinforced composites

\begin{tabular}{|c|c|c|c|c|c|c|}
\hline $\begin{array}{c}\text { Cement } \\
\text { type }\end{array}$ & Group & $\begin{array}{c}\text { Sand-cement } \\
\text { mass ratio }\end{array}$ & $\begin{array}{c}\text { Water-cement } \\
\text { mass ratio }\end{array}$ & $\begin{array}{c}\text { Fibre volume } \\
\text { fraction }\end{array}$ & $\begin{array}{c}\text { Retarder } \\
\text { dosage }\end{array}$ & Test \\
\hline \multirow{11}{*}{ MPPC } & M-S/C-0.8 & 0.8 & \multirow{3}{*}{0.16} & \multirow{3}{*}{$1.2 \%$} & \multirow{3}{*}{$9.0 \%$} & $S \& F$ \\
\hline & $\mathrm{M}-\mathrm{S} / \mathrm{C}-1.0$ & 1.0 & & & & $S \& F$ \\
\hline & $\mathrm{M}-\mathrm{S} / \mathrm{C}-1.2$ & 1.2 & & & & $S \& F$ \\
\hline & $\mathrm{M}-\mathrm{W} / \mathrm{C}-0.16$ & \multirow{3}{*}{1.0} & 0.16 & \multirow{3}{*}{$1.2 \%$} & \multirow{3}{*}{$9.0 \%$} & $\overline{S \& F}$ \\
\hline & $\mathrm{M}-\mathrm{W} / \mathrm{C}-0.18$ & & 0.18 & & & $S \& F$ \\
\hline & $\mathrm{M}-\mathrm{W} / \mathrm{C}-0.20$ & & 0.20 & & & $S \& F$ \\
\hline & M-F-0.0\% & \multirow{5}{*}{1.0} & \multirow{5}{*}{0.16} & $0.0 \%$ & \multirow{5}{*}{$9.0 \%$} & $\bar{S}$ \\
\hline & M-F- $0.4 \%$ & & & $0.4 \%$ & & $\mathrm{~S}$ \\
\hline & M-F- $0.8 \%$ & & & $0.8 \%$ & & $S \& F$ \\
\hline & $\mathrm{M}-\mathrm{F}-1.2 \%$ & & & $1.2 \%$ & & $S \& F$ \\
\hline & $\mathrm{M}-\mathrm{F}-1.6 \%$ & & & $1.6 \%$ & & $S \& F$ \\
\hline \multirow{5}{*}{ SAC } & S-F-0.0\% & \multirow{5}{*}{1.0} & \multirow{5}{*}{0.35} & $0.0 \%$ & \multirow{5}{*}{$0.0 \%$} & $\mathrm{~S}$ \\
\hline & S-F- $0.4 \%$ & & & $0.4 \%$ & & $\mathrm{~S}$ \\
\hline & S-F- $0.8 \%$ & & & $0.8 \%$ & & $S \& F$ \\
\hline & S-F-1.2\% & & & $1.2 \%$ & & $S \& F$ \\
\hline & S-F-1.6\% & & & $1.6 \%$ & & $S \& F$ \\
\hline \multirow{5}{*}{$\mathrm{OPC}$} & P-F-0.0\% & \multirow{5}{*}{1.0} & \multirow{5}{*}{0.37} & $0.0 \%$ & \multirow{5}{*}{$0.0 \%$} & $\mathrm{~S}$ \\
\hline & P-F-0.4\% & & & $0.4 \%$ & & $\mathrm{~S}$ \\
\hline & P-F- $0.8 \%$ & & & $0.8 \%$ & & $S \& F$ \\
\hline & P-F-1.2\% & & & $1.2 \%$ & & $S \& F$ \\
\hline & P-F-1.6\% & & & $1.6 \%$ & & $S \& F$ \\
\hline
\end{tabular}

Note: Retarder dosage for all the MPPC composites is $9.0 \%$ of $\mathrm{MgO}$ by mass. The magnesium 
654 Slump, average compressive strength and flexural strength of MSFRMC

\begin{tabular}{ccccccccccccc}
\hline \multirow{2}{*}{ Group } & \multirow{2}{*}{$\begin{array}{c}\text { Slump } \\
(\mathrm{mm})\end{array}$} & \multicolumn{4}{c}{$\begin{array}{c}\text { Average compressive strength (MPa) for } \\
\text { curing period of }\end{array}$} & \multicolumn{5}{c}{$\begin{array}{c}\text { Average flexural strength (MPa) for } \\
\text { curing period of }\end{array}$} \\
\cline { 3 - 14 } & & 6 hours & 12 hours & 1 day & 3 days & 7 days & 6 hours & 12 hours & 1 day & 3 days & 7 days \\
\hline M-S/C-0.8 & 45 & 33.3 & 37.4 & 39.0 & 51.6 & 55.1 & 8.8 & 11.3 & 12.1 & 14.7 & 20.7 \\
M-S/C-1.0 & 38 & 36.1 & 39.1 & 45.4 & 49.7 & 56.4 & 11.0 & 12.7 & 13.9 & 18.6 & 20.9 \\
M-S/C-1.2 & 32 & 31.0 & 34.7 & 41.4 & 45.6 & 46.2 & 7.6 & 8.8 & 11.4 & 12.4 & 15.2 \\
\hline M-W/C-0.16 & 28 & 39.7 & 43.0 & 49.9 & 54.7 & 62.0 & 12.1 & 14.0 & 16.2 & 20.5 & 23.0 \\
M-W/C-0.18 & 38 & 36.1 & 39.1 & 45.4 & 49.7 & 56.4 & 11.0 & 12.7 & 13.9 & 18.6 & 20.9 \\
M-W/C-0.20 & 52 & 30.9 & 32.3 & 35.8 & 44.3 & 49.4 & 10.7 & 11.7 & 12.4 & 14.7 & 18.3 \\
\hline M-F-0.0\% & 57 & 18.2 & 21.6 & 26.3 & 29.8 & 33.1 & 3.1 & 3.7 & 4.4 & 4.7 & 5.9 \\
M-F-0.4\% & 62 & 22.1 & 28.9 & 31.2 & 36.9 & 43.5 & 5.9 & 7.3 & 8.3 & 9.2 & 10.2 \\
M-F-0.8\% & 49 & 29.8 & 32.3 & 35.1 & 44.6 & 49.2 & 8.7 & 10.7 & 11.7 & 12.2 & 12.5 \\
M-F-1.2\% & 38 & 36.1 & 39.1 & 45.4 & 49.7 & 56.4 & 11.0 & 12.7 & 13.9 & 18.6 & 20.9 \\
M-F-1.6\% & 24 & 37.3 & 40.9 & 46.7 & 50.8 & 56.2 & 12.3 & 16.3 & 17.3 & 19.4 & 22.4 \\
\hline
\end{tabular}


658 Slump and average compressive strength of SAC composite with varying volume fractions of MSF

\begin{tabular}{cccccc}
\hline Group & S-F-0.0\% & S-F-0.4\% & S-F-0.8\% & S-F-1.2\% & S-F-1.6\% \\
\hline Fibre volume fraction & $0.0 \%$ & $0.4 \%$ & $0.8 \%$ & $1.2 \%$ & $1.6 \%$ \\
\hline Slump (mm) & 41 & 43 & 37 & 21 & 15 \\
\hline $\begin{array}{c}\text { Average compressive } \\
\text { strength (MPa) }\end{array}$ & 41.2 & 42.9 & 44.8 & 49.1 & 54.5 \\
\hline
\end{tabular}

659 Note: The reported values of strength are the average values of three specimens for each Group. Only the compressive strength was tested for the SAC based composites. 
663 Slump and average compressive strength of OPC composite with varying volume fractions of MSF

\begin{tabular}{cccccc}
\hline Group & P-F-0.0\% & P-F-0.4\% & P-F-0.8\% & P-F-1.2\% & P-F-1.6\% \\
\hline Fibre volume fraction & $0.0 \%$ & $0.4 \%$ & $0.8 \%$ & $1.2 \%$ & $1.6 \%$ \\
\hline Slump (mm) & 151 & 146 & 135 & 117 & 102 \\
\hline $\begin{array}{c}\text { Average compressive strength } \\
(\mathrm{MPa})\end{array}$ & 42.8 & 46.2 & 48.3 & 49.4 & 53.4 \\
\hline
\end{tabular}

664 Note: The reported values of strength are the average values of three specimens for each Group. Only the compressive strength was tested for the OPC based composites. 
668 Flexural toughness and ductility index of MSF reinforced composites

\begin{tabular}{|c|c|c|c|c|}
\hline Group & $\begin{array}{c}\text { Fibre } \\
\text { volume fraction }\end{array}$ & Curing time & $\begin{array}{l}\text { Flexural toughness } \\
T_{150}^{D}(\mathrm{kN} \cdot \mathrm{mm})\end{array}$ & $\begin{array}{l}\text { Equivalent flexural strength } \\
\quad \text { ratio } R_{T, 150}^{D}(\%)\end{array}$ \\
\hline M-S/C-0.8 & \multirow{3}{*}{$1.2 \%$} & \multirow{3}{*}{7 days } & 31.52 & 68.8 \\
\hline $\mathrm{M}-\mathrm{S} / \mathrm{C}-1.0$ & & & 30.63 & 66.6 \\
\hline M-S/C-1.2 & & & 26.04 & 62.0 \\
\hline $\mathrm{M}-\mathrm{W} / \mathrm{C}-0.16$ & \multirow{3}{*}{$1.2 \%$} & \multirow{3}{*}{7 days } & 32.18 & 64.2 \\
\hline M-W/C-0.18 & & & 30.63 & 66.6 \\
\hline $\mathrm{M}-\mathrm{W} / \mathrm{C}-0.20$ & & & 28.15 & 69.1 \\
\hline M-F-0.8\% & $0.8 \%$ & \multirow{3}{*}{7 days } & 21.35 & 48.8 \\
\hline $\mathrm{M}-\mathrm{F}-1.2 \%$ & $1.2 \%$ & & 30.63 & 66.6 \\
\hline M-F-1.6\% & $1.6 \%$ & & 43.67 & 75.3 \\
\hline \multirow{3}{*}{$\mathrm{M}-\mathrm{F}-1.2 \%$} & \multirow{3}{*}{$1.2 \%$} & 1 day & 25.34 & 62.0 \\
\hline & & 3 days & 28.40 & 67.0 \\
\hline & & 7 days & 30.63 & 66.6 \\
\hline S-F-0.8\% & $0.8 \%$ & \multirow{3}{*}{7 days } & 24.87 & 61.5 \\
\hline S-F-1.2\% & $1.2 \%$ & & 28.69 & 61.9 \\
\hline S-F-1.6\% & $1.6 \%$ & & 37.92 & 69.6 \\
\hline P-F- $0.8 \%$ & $0.8 \%$ & \multirow{3}{*}{7 days } & 27.99 & 70.8 \\
\hline P-F-1.2\% & $1.2 \%$ & & 33.45 & 75.9 \\
\hline P-F-1.6\% & $1.6 \%$ & & 38.74 & 76.9 \\
\hline
\end{tabular}

Note: The reported values are the average values of three specimens for each Group. 


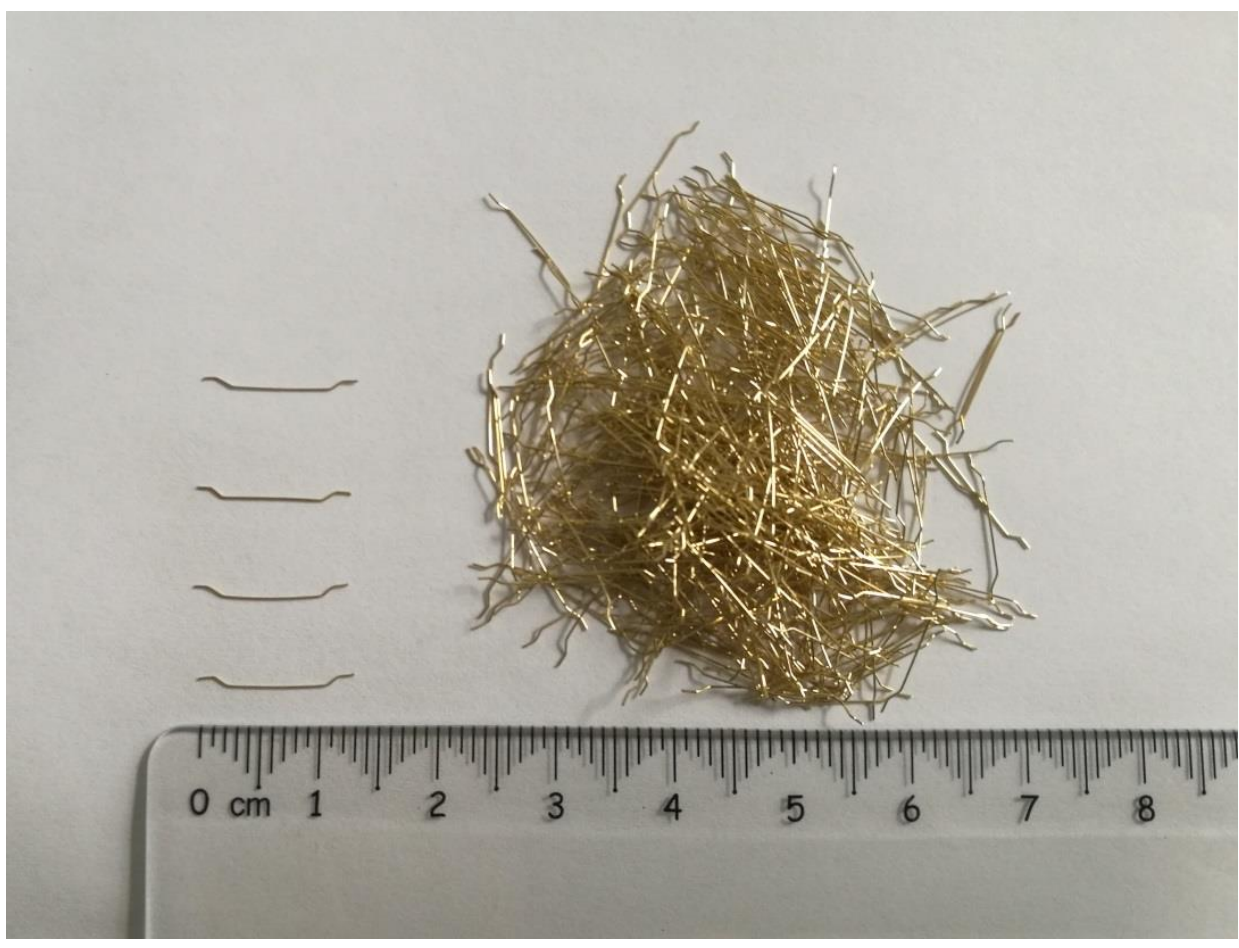

Figure 1 Micro-steel fibres 


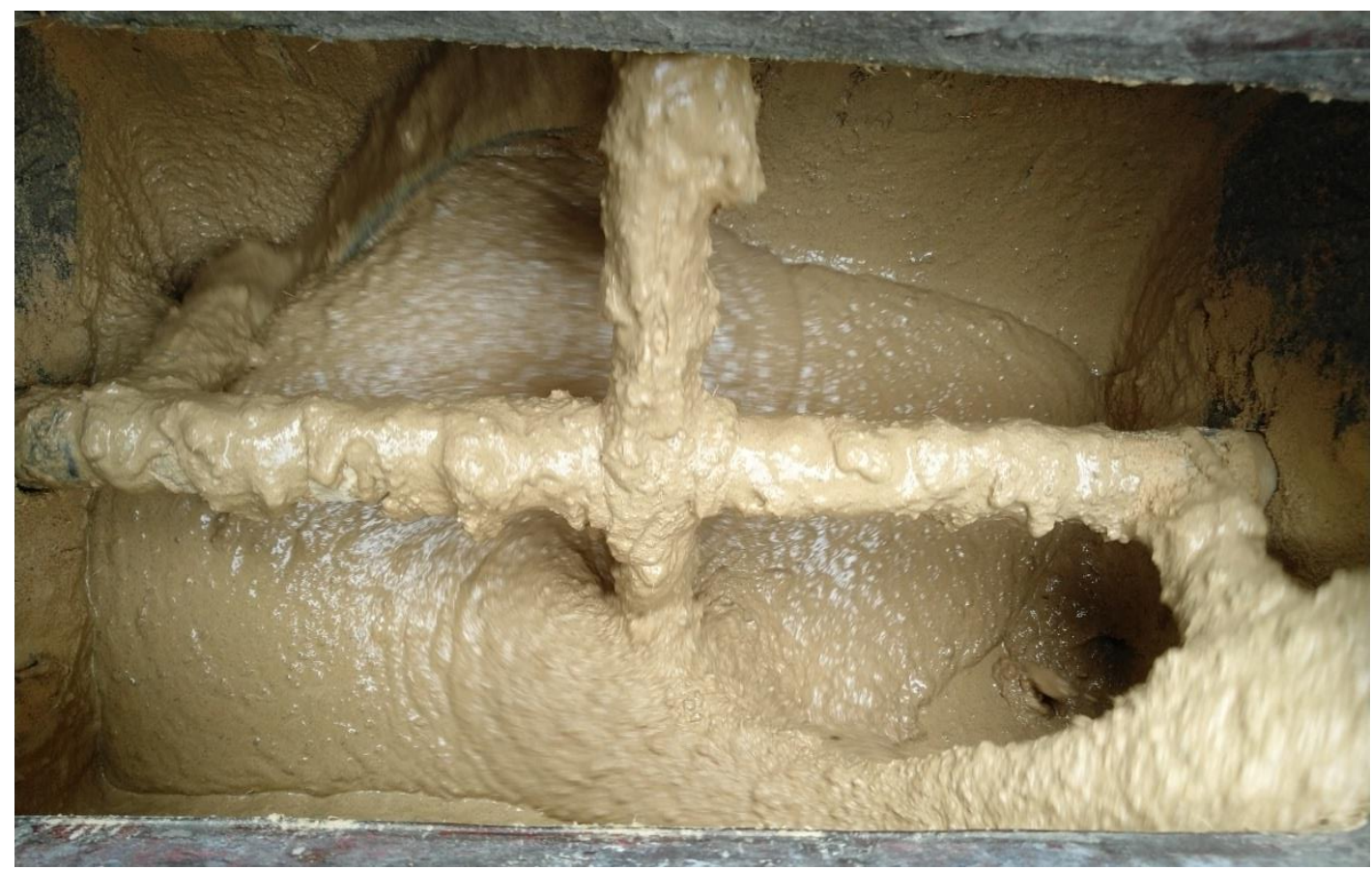




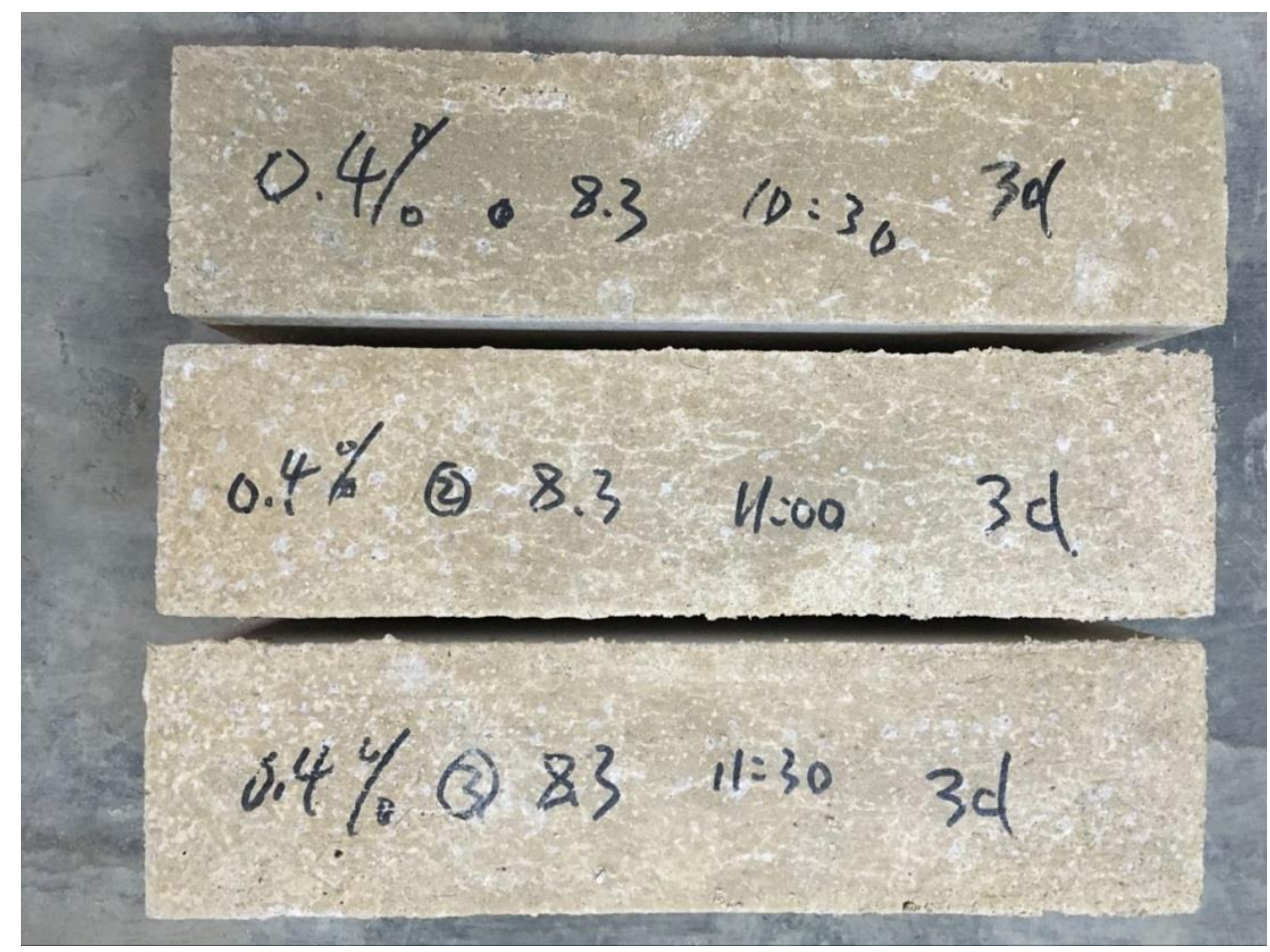



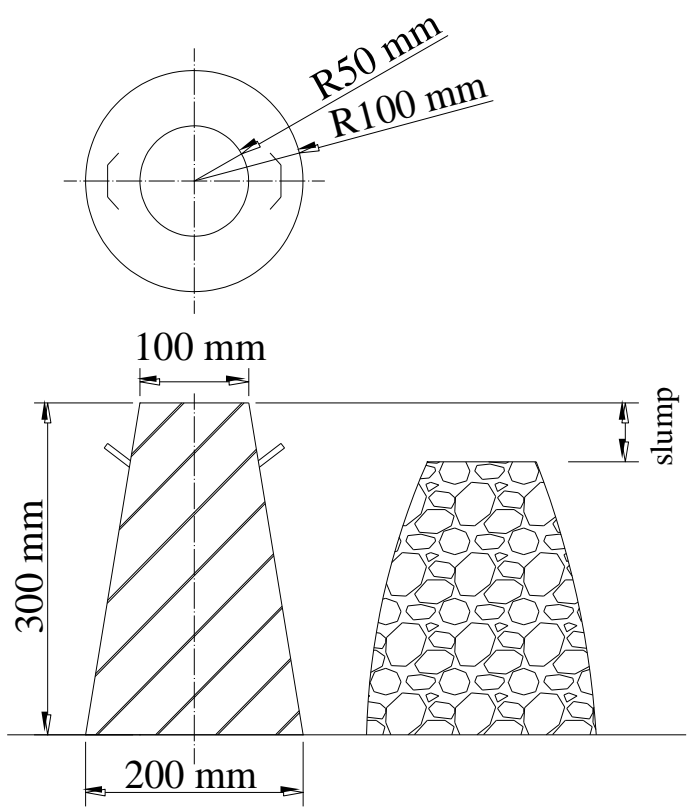

(a)

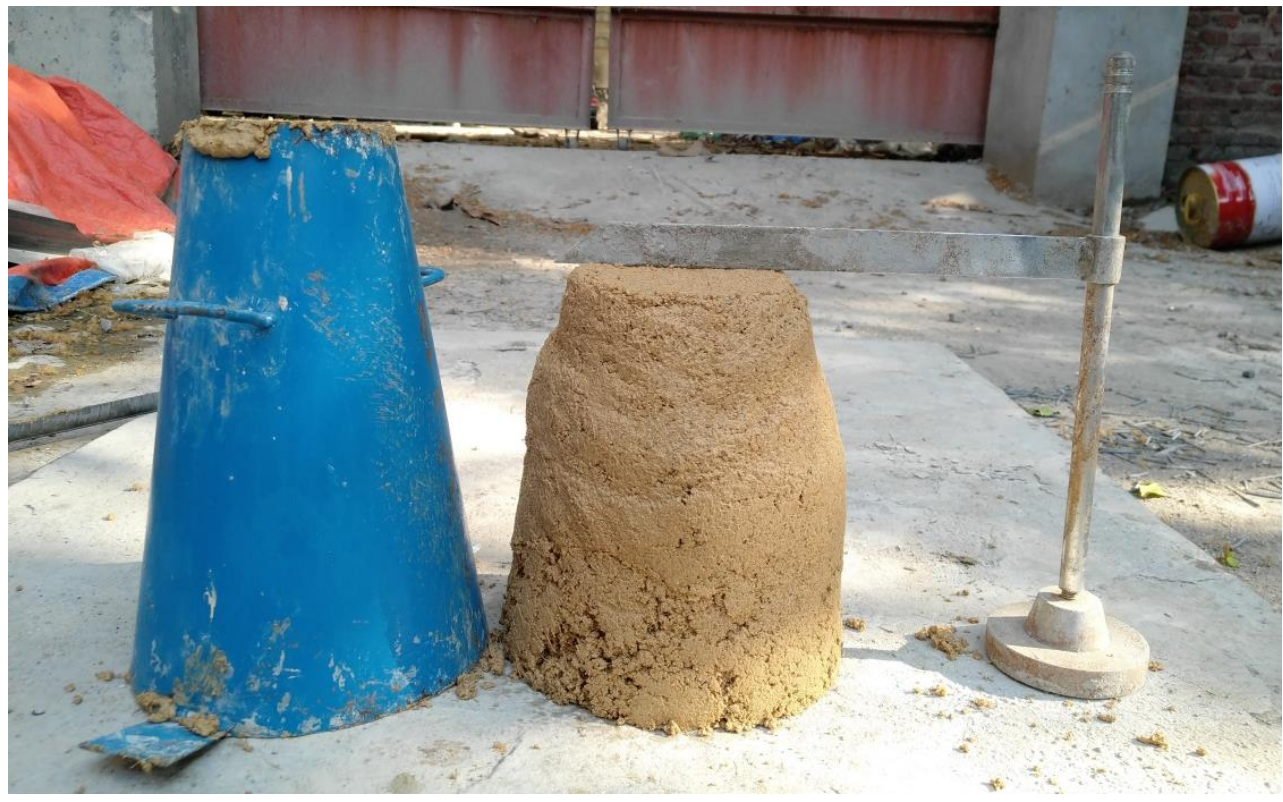

(b)

Figure 4 Slump test: (a) Schematic representation of slump measurement; (b) Photo of the slump measurement 


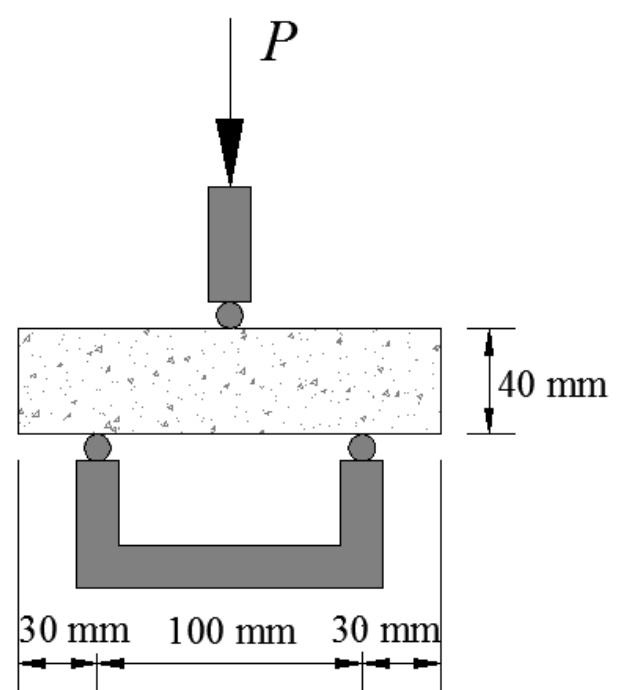

(a)

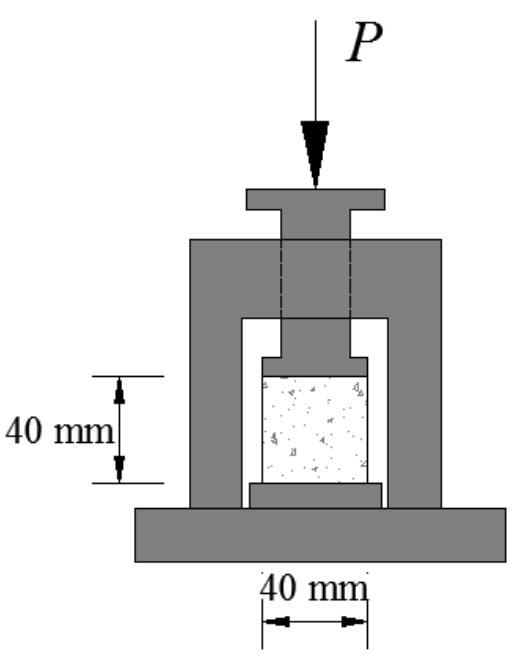

(b)
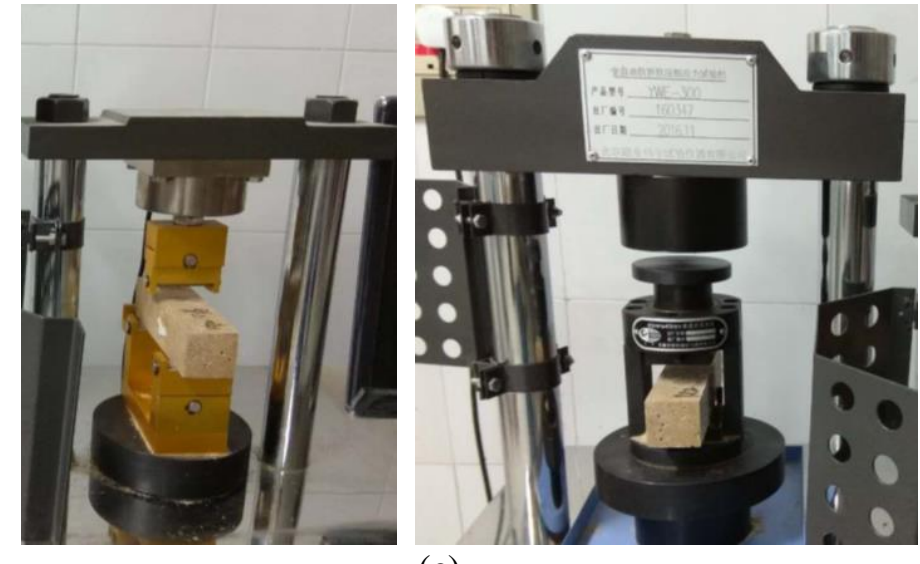

(c)

Figure 5 Flexural and Compressive strength test:

(a) Schematic representation of flexural strength test, (b) Schematic representation of compressive strength test and (c) Photo of the test 


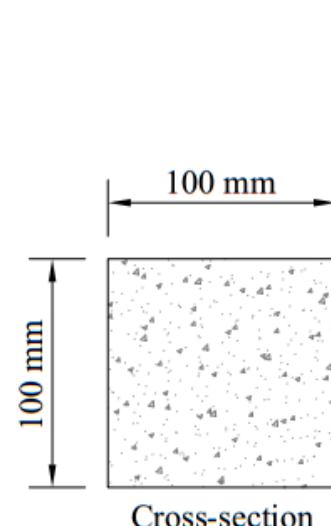

Cross-section

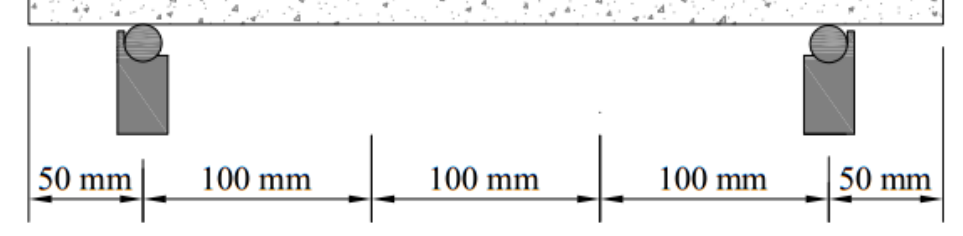

(a)

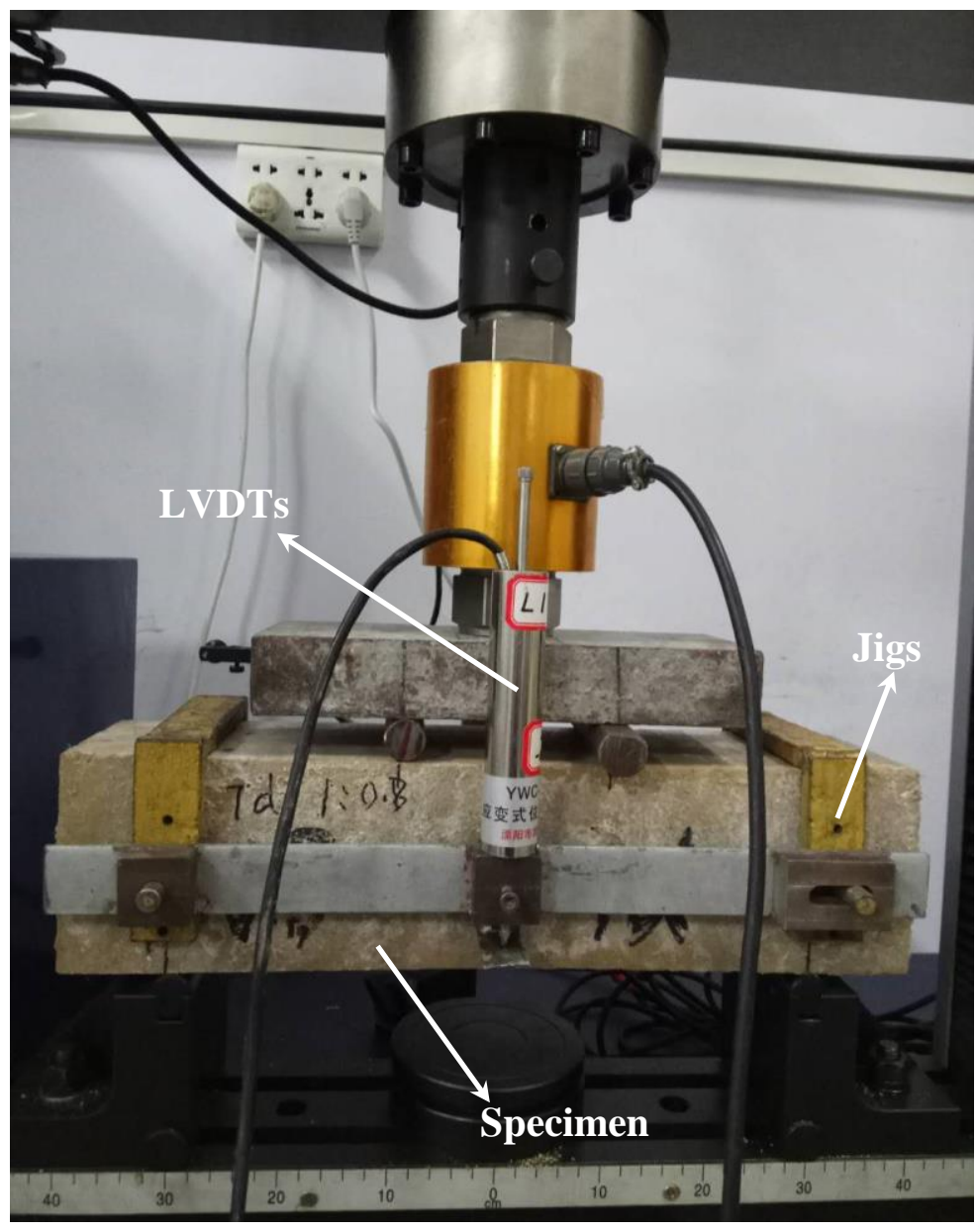

(b)

Figure 6 Flexural toughness test: (a) Schematic representation and (b) Photo of the test 
697

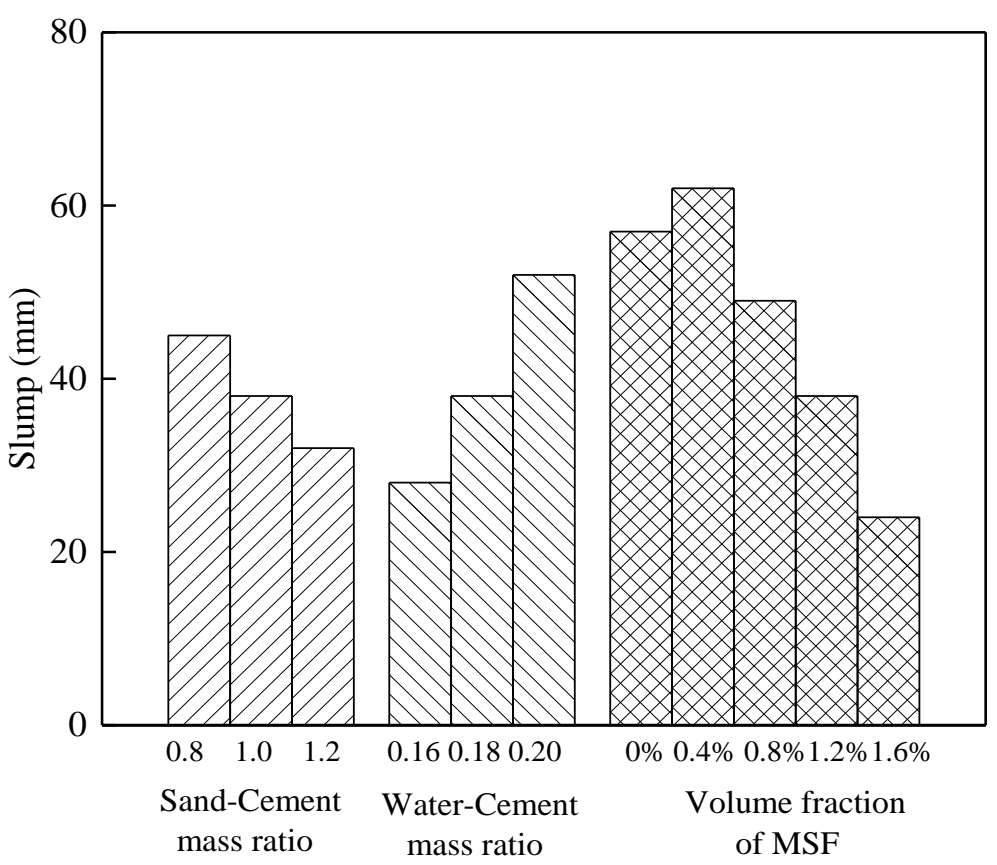

700

Figure 7 Slumps of the mixtures prepared with MPPC 


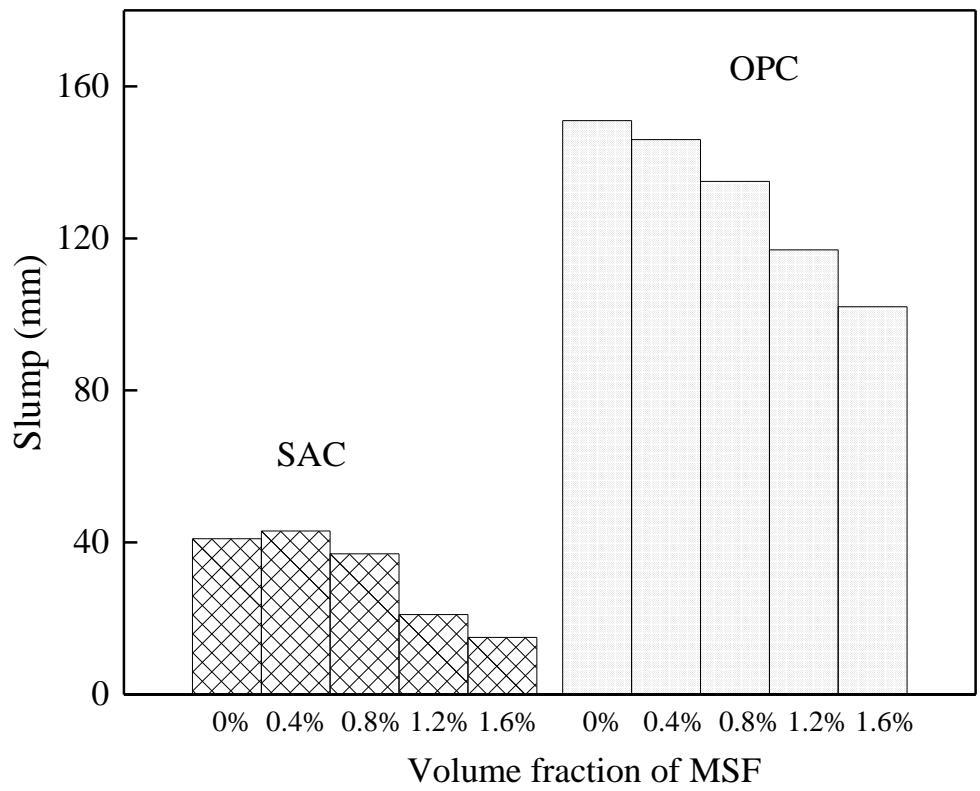

Volume fraction of MSF

Figure 8 Slumps of the mixtures prepared with SAC and OPC with varying volume fraction of MSF 


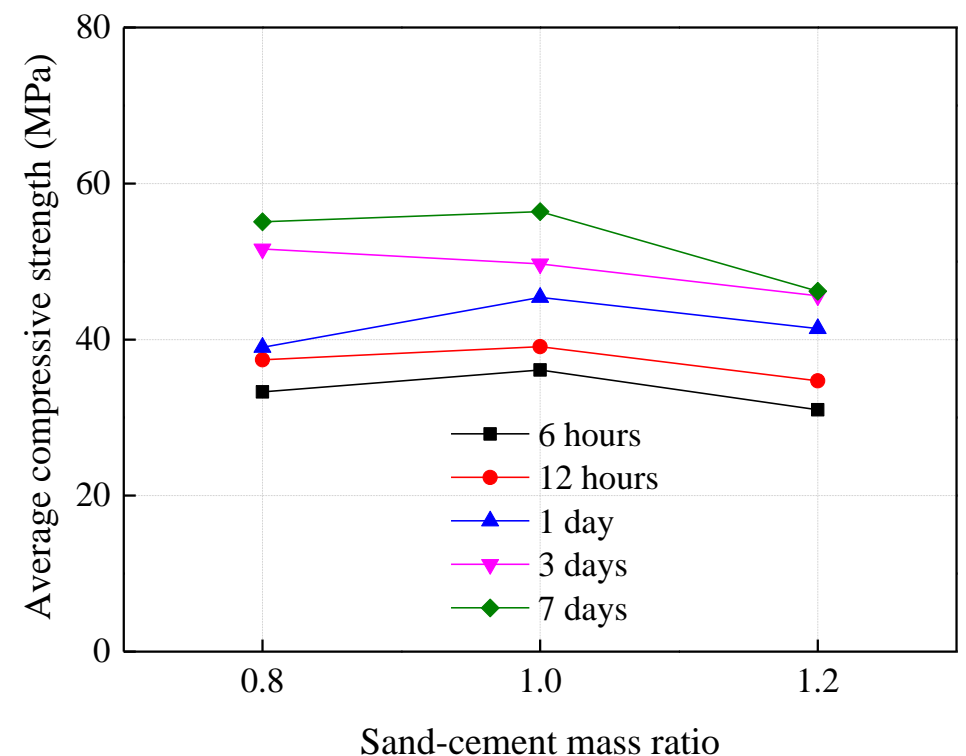

(a)

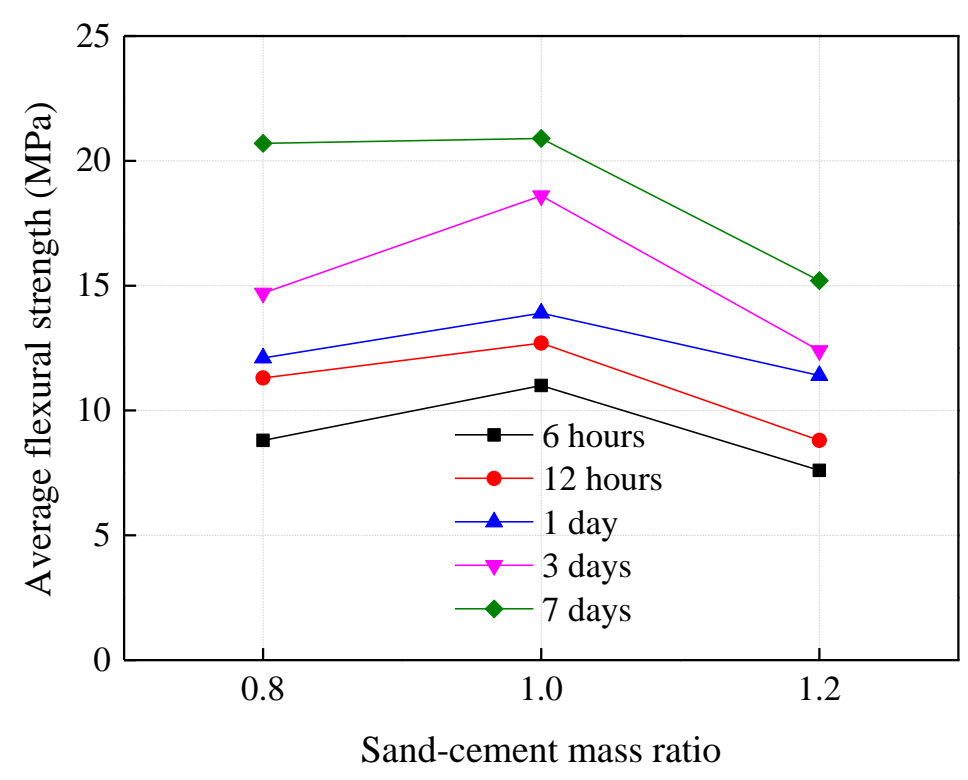

(b)

Figure 9 Effect of sand-cement mass ratio on: (a) average compressive strength and (b) average 


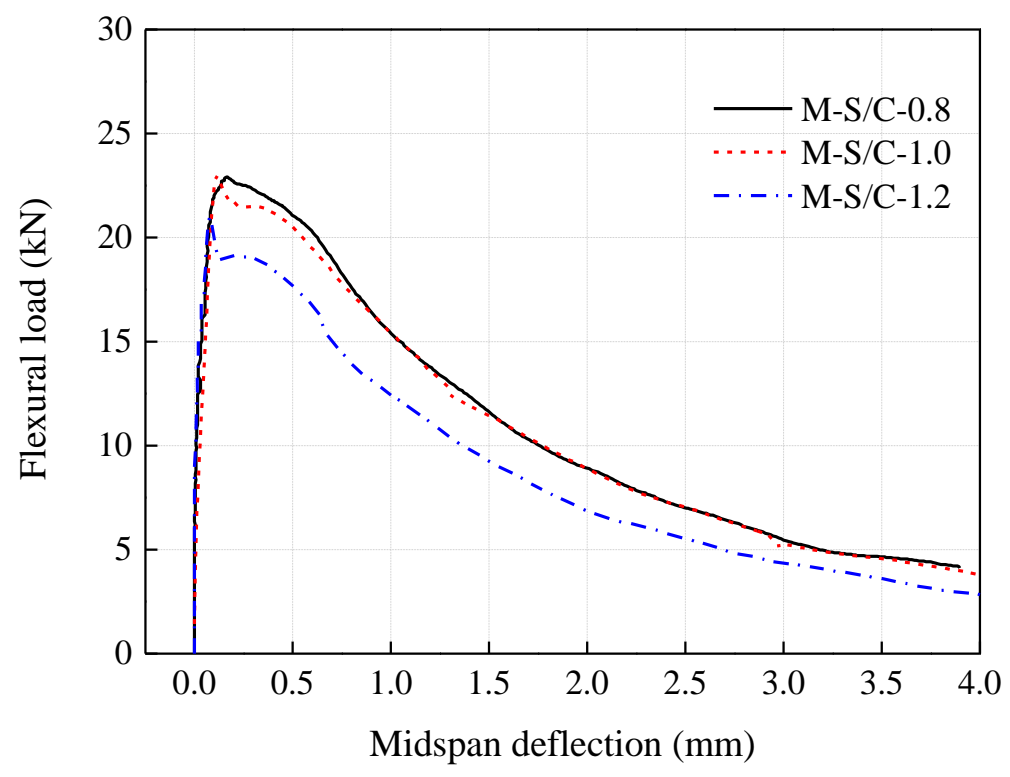

Figure 10 Effect of sand-cement mass ratio on flexural load versus midspan deflection of MSFRMC cured for 7 days 


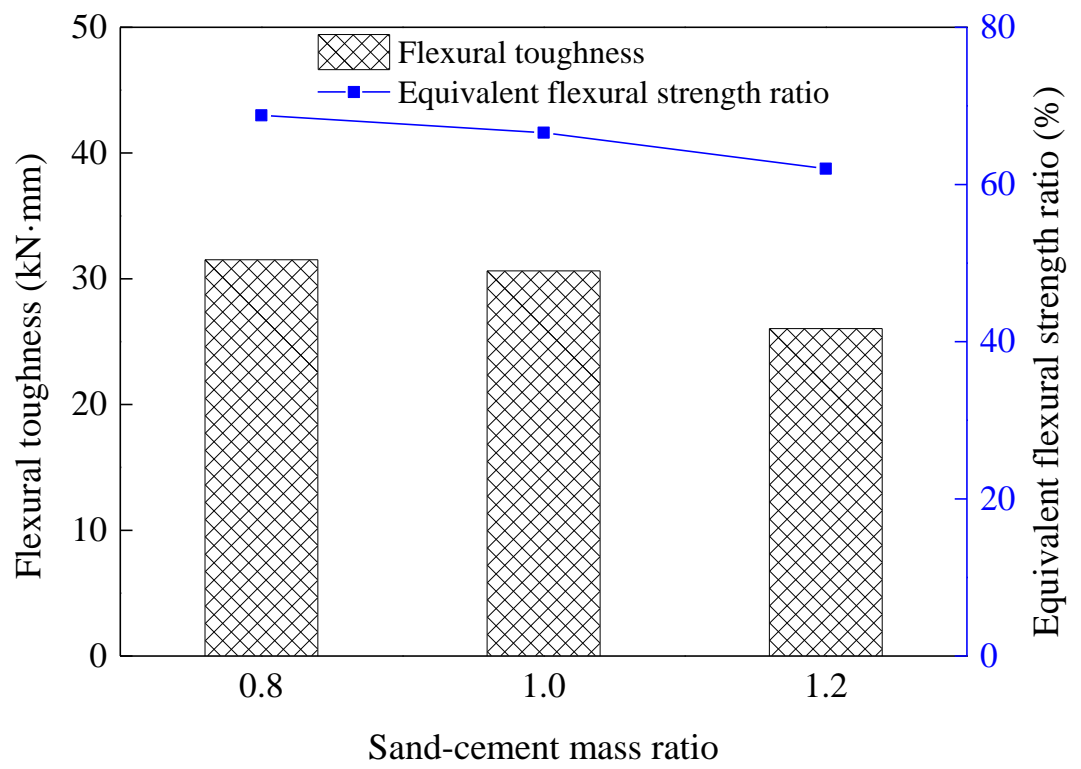

719

Figure 11 Effect of sand-cement mass ratio on flexural toughness and ductility of MSFRMC cured for 721 7 days 


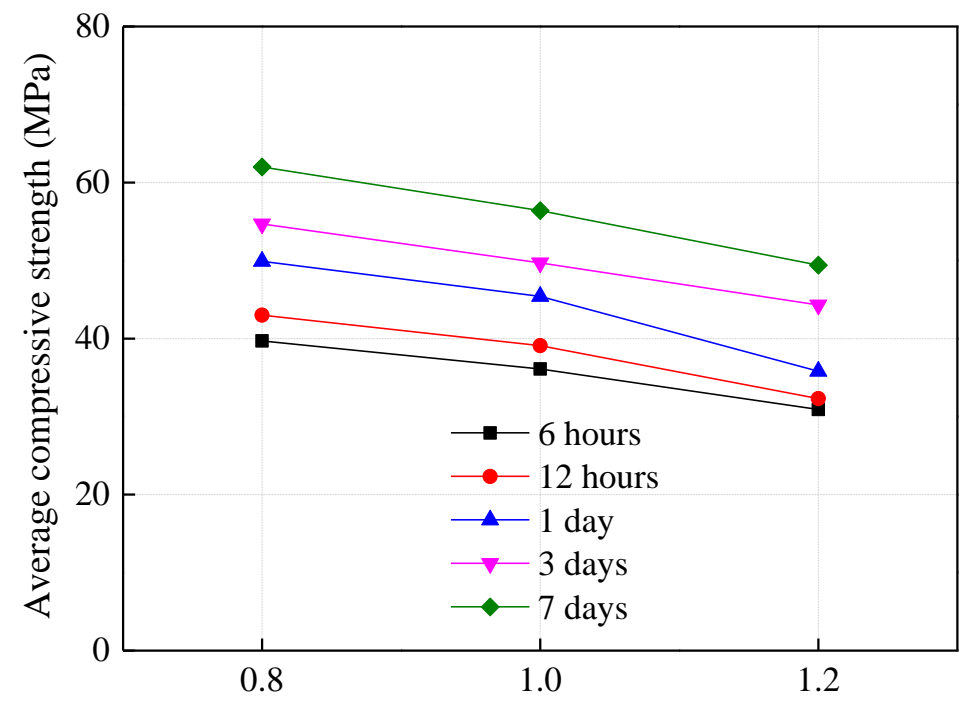

Water-cement mass ratio

(a)

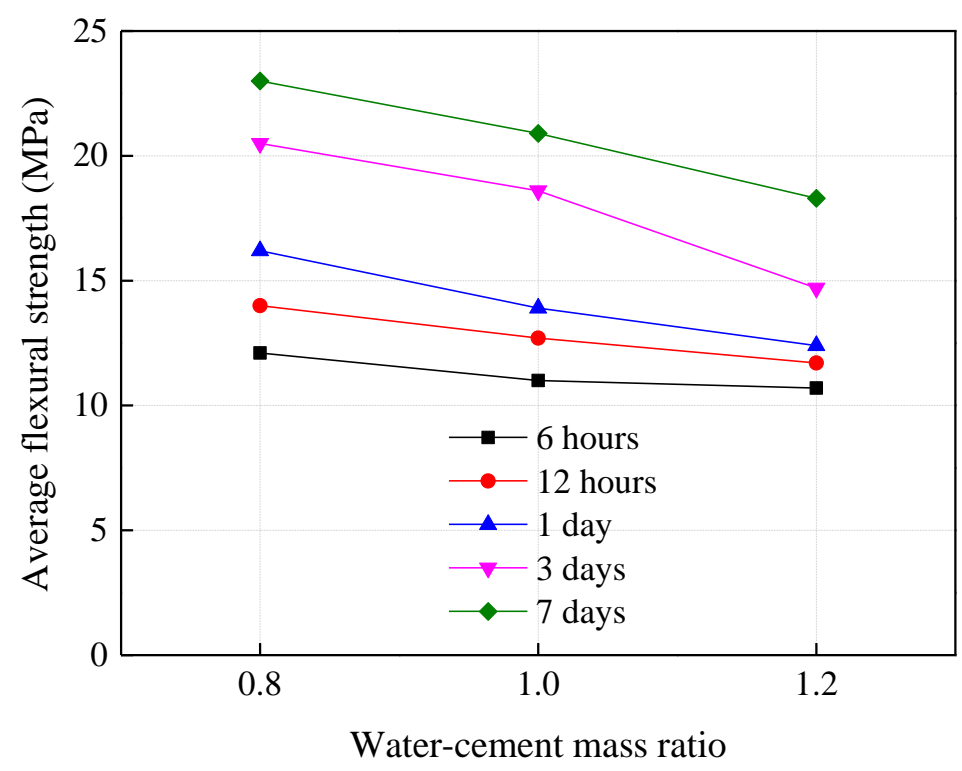

(b)

Figure 12 Effect of water-cement mass ratio on: (a) average compressive strength and (b) average 


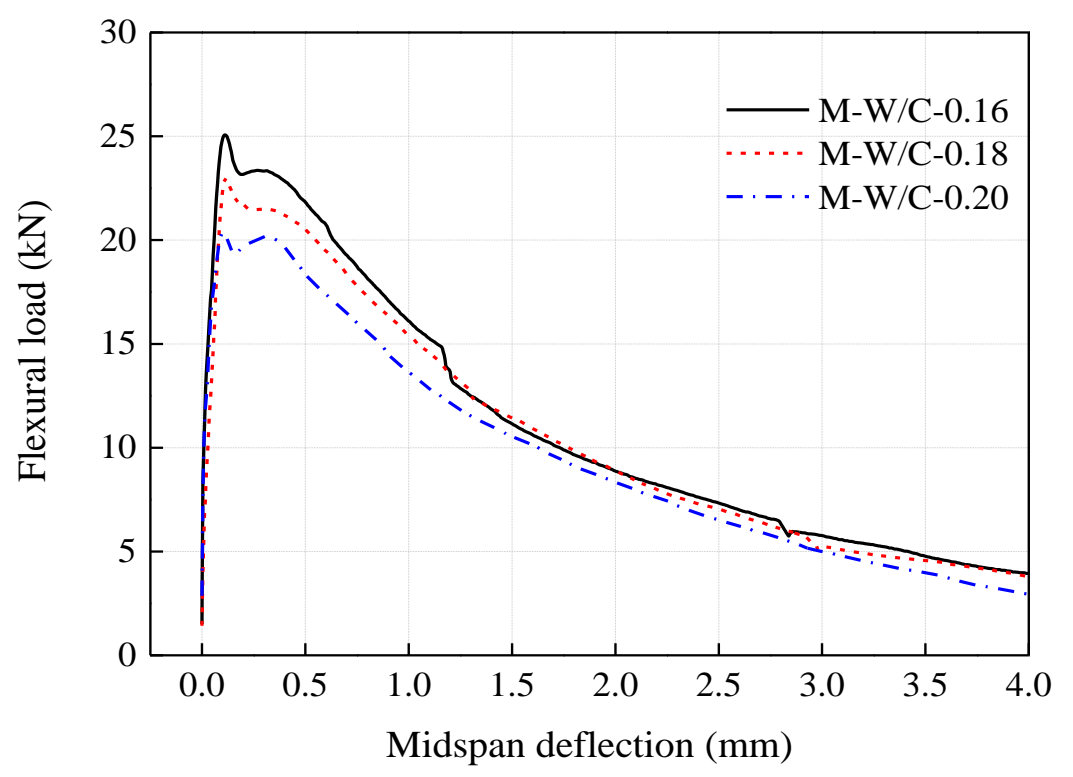

732

Figure 13 Effect of water-cement mass ratio on flexural load versus midspan deflection of MSFRMC cured for 7 days 


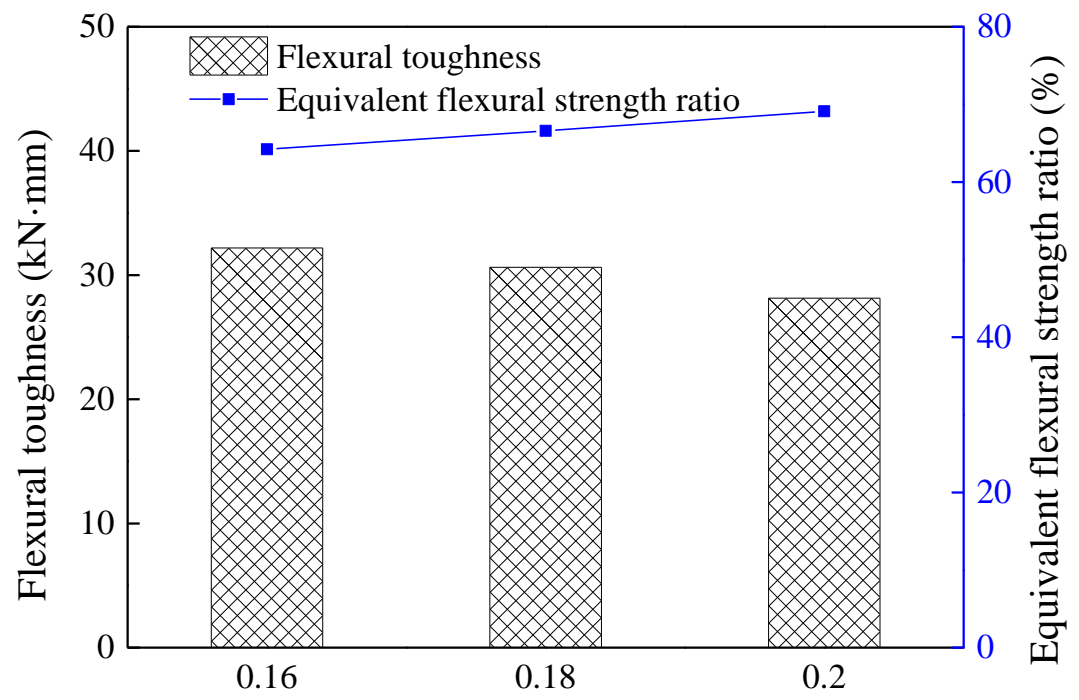

Water-cement mass ratio

738 Figure 14 Effect of water-cement mass ratio on flexural toughness and ductility of MSFRMC cured for 7 days 


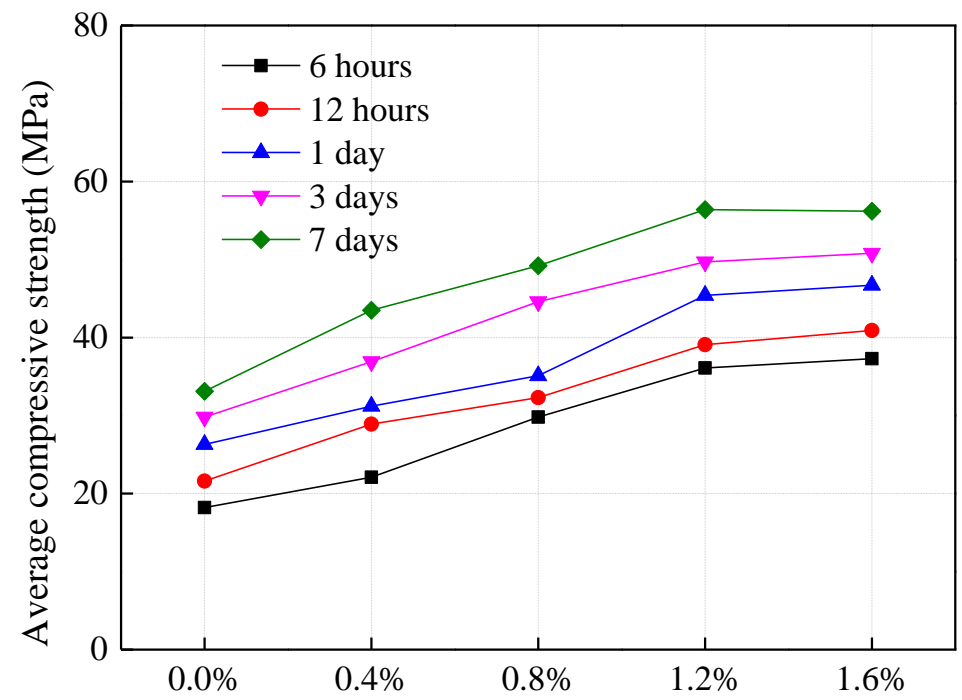

Volume fraction of MSF

(a)

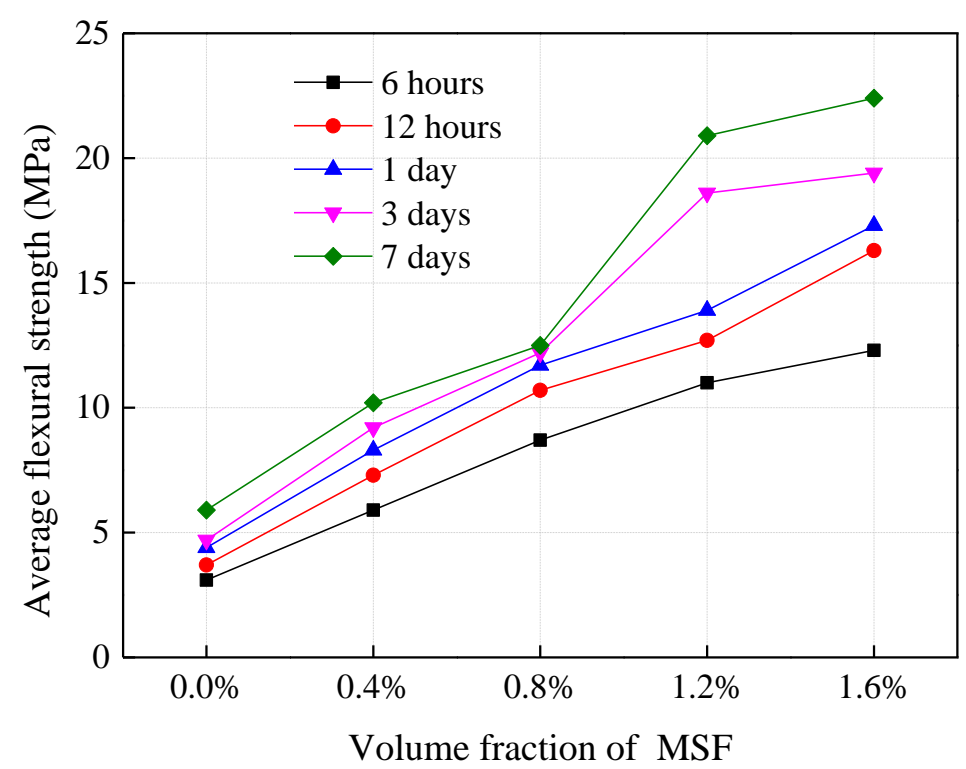

(b)

Figure 15 Effect of volume fraction of MSF on: (a) average compressive strength and (b) average flexural strength 


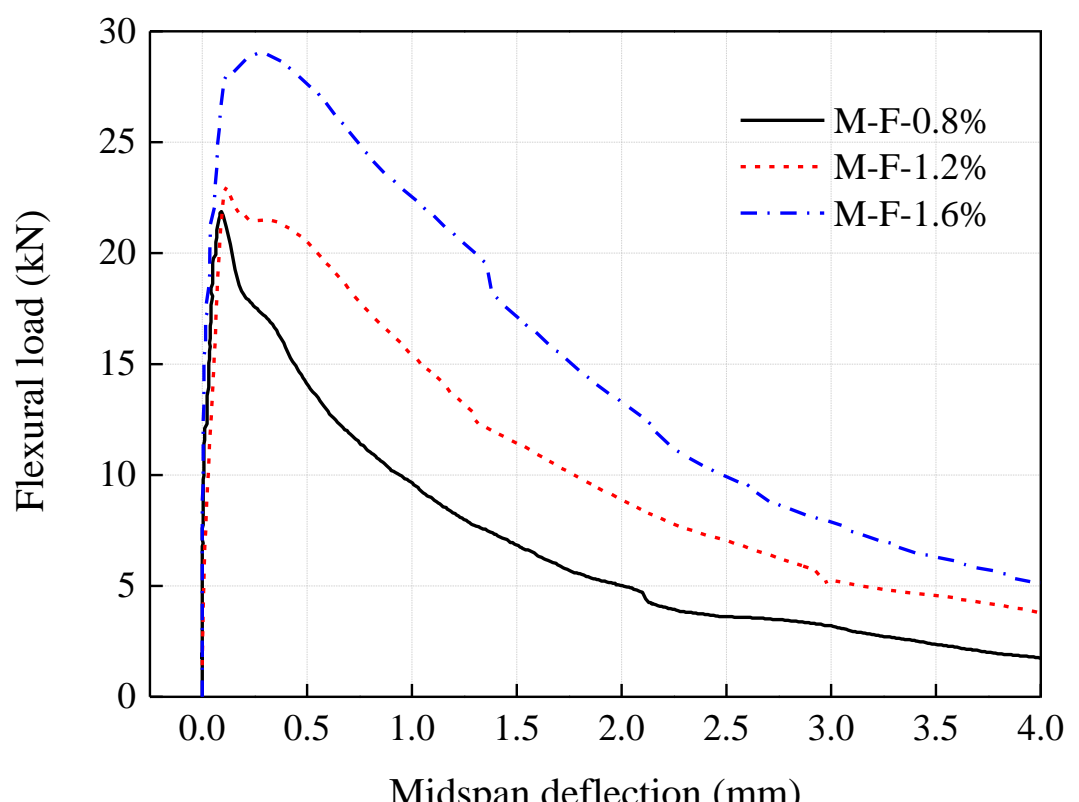

Figure 16 Effect of volume fraction of MSF on flexural load versus midspan deflection of MSFRMC cured for 7 days 


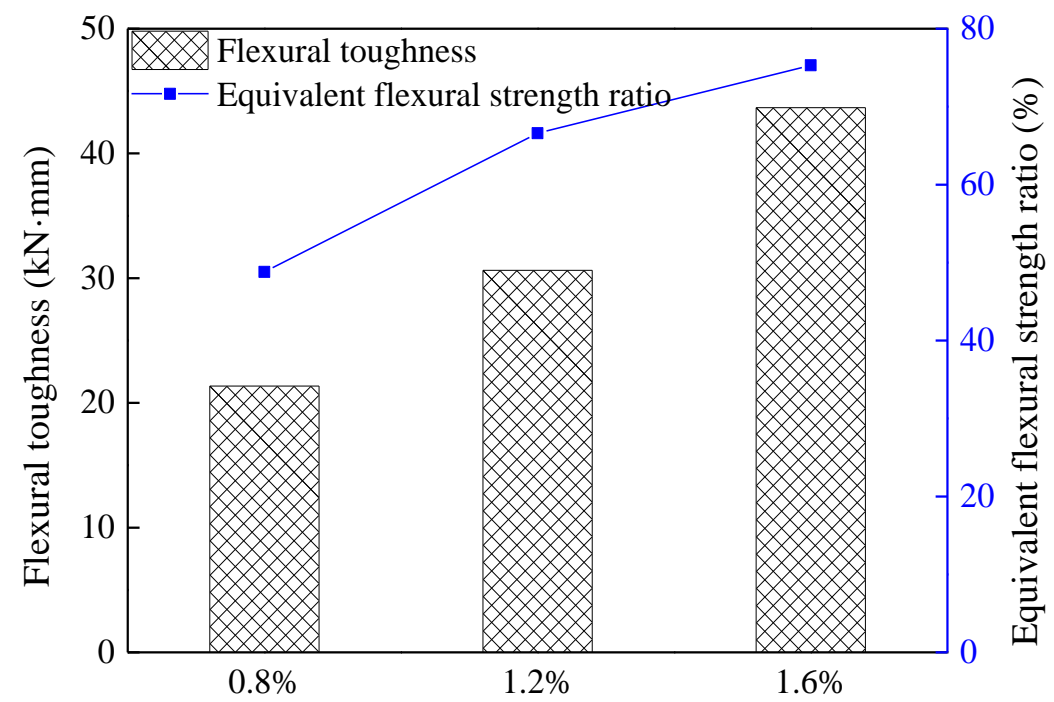

Volume fraction of MSF

753
754

755

756
Figure 17 Effect of volume fraction of MSF on flexural toughness and ductility of MSFRMC cured for 7 days 


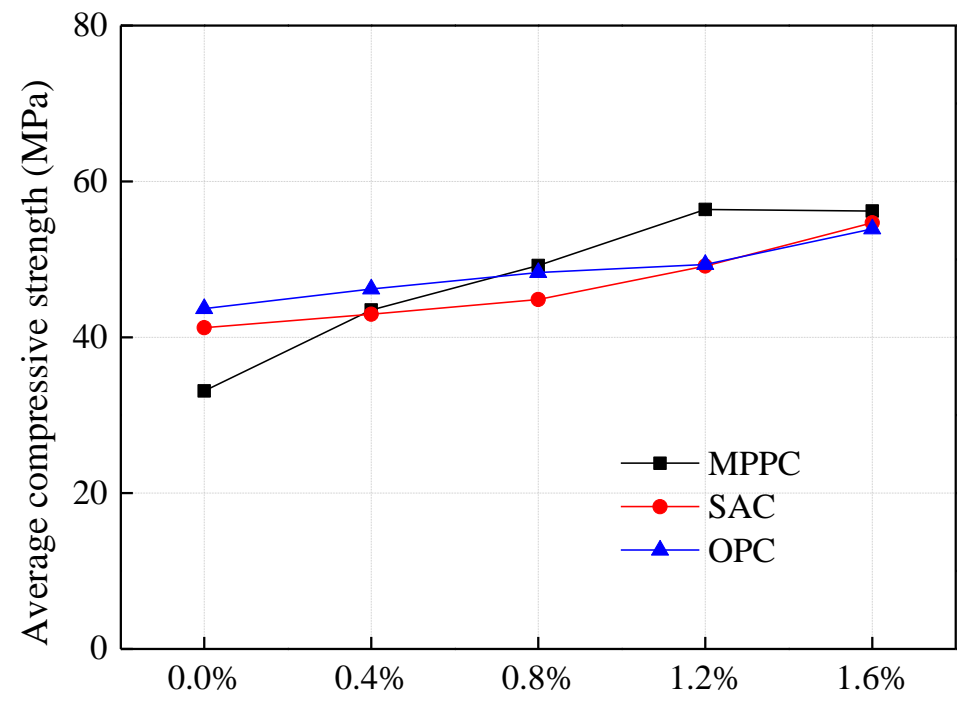

Volume fraction of MSF

Figure 18 Effect of volume fraction of MSF on the average compressive strength for MPPC-based, SAC-based and OPC-based composites cured for 7 days 


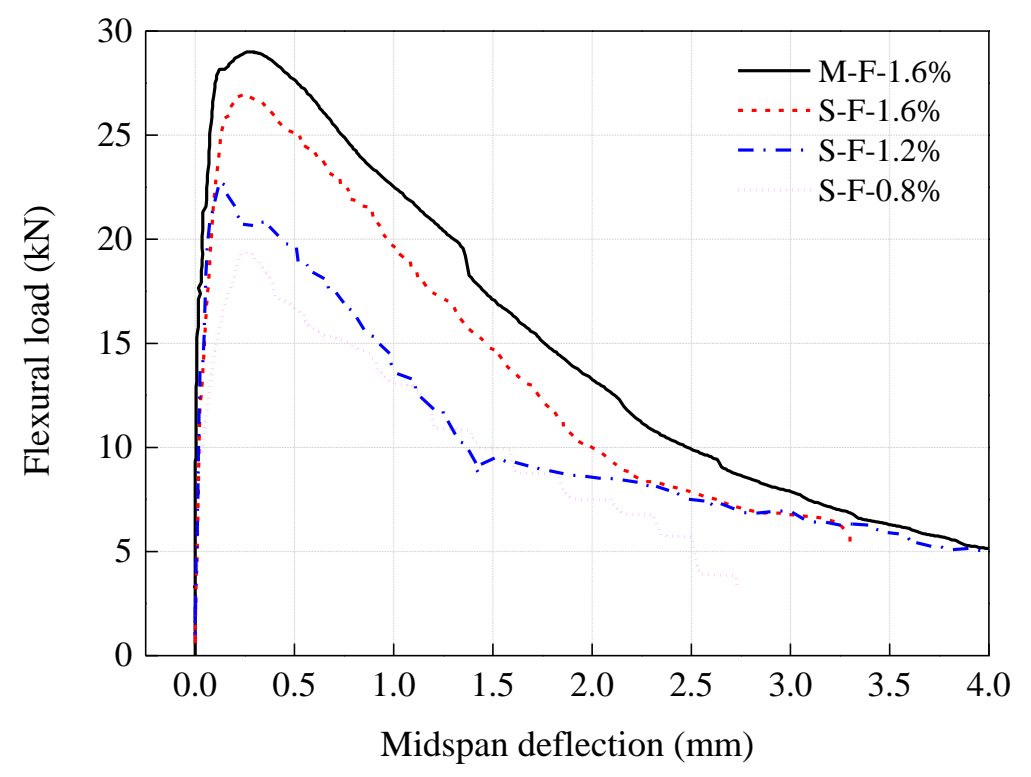

763
764

764
765

Figure 19 Effect of volume fraction of MSF on flexural load versus midspan deflection of SAC based composites cured for 7 days 


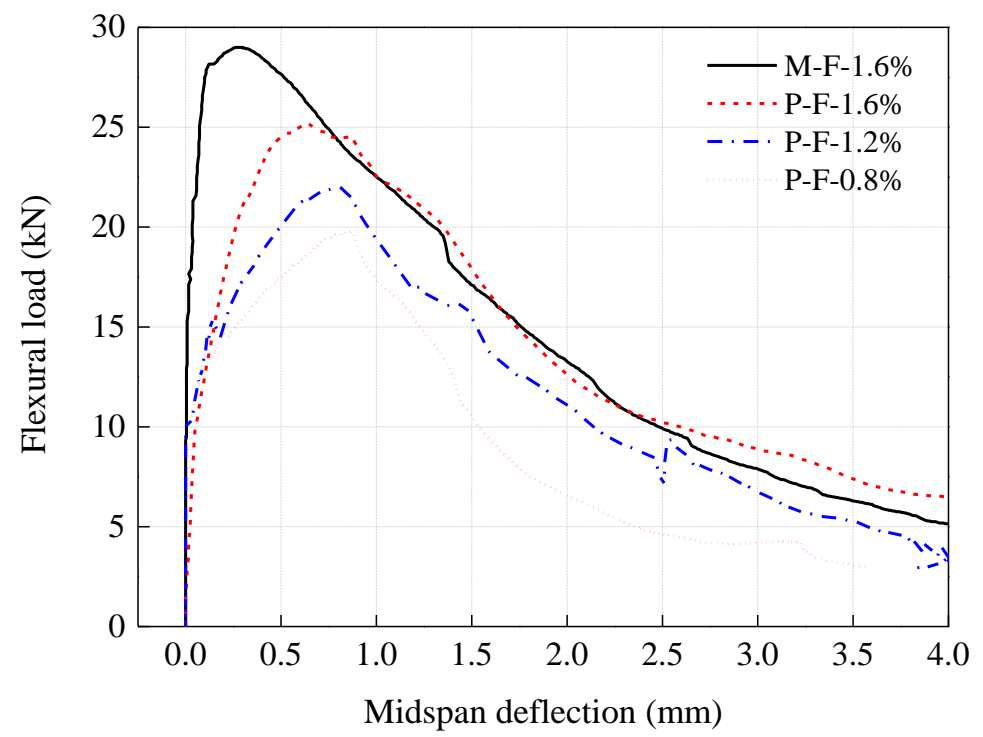

768

Figure 20 Effect of volume fraction of MSF on flexural load versus midspan deflection of OPC based composites cured for 7 days 


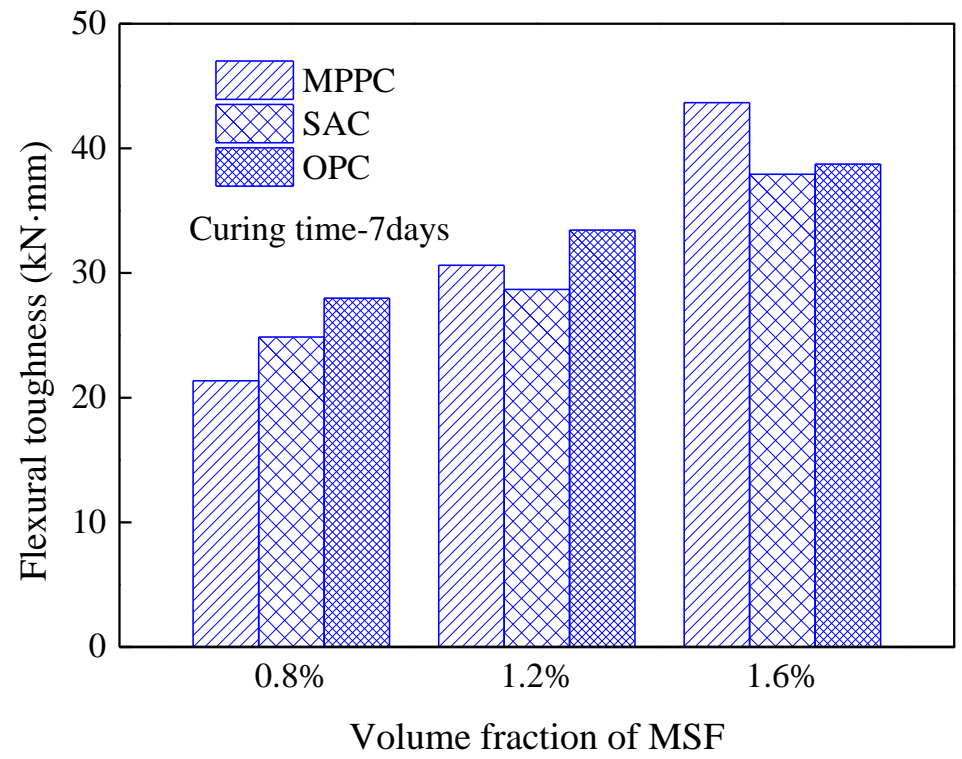

773

774

775

Figure 21 Flexural toughness of different cements based composites with varying volume fraction of MSF cured for 7days 


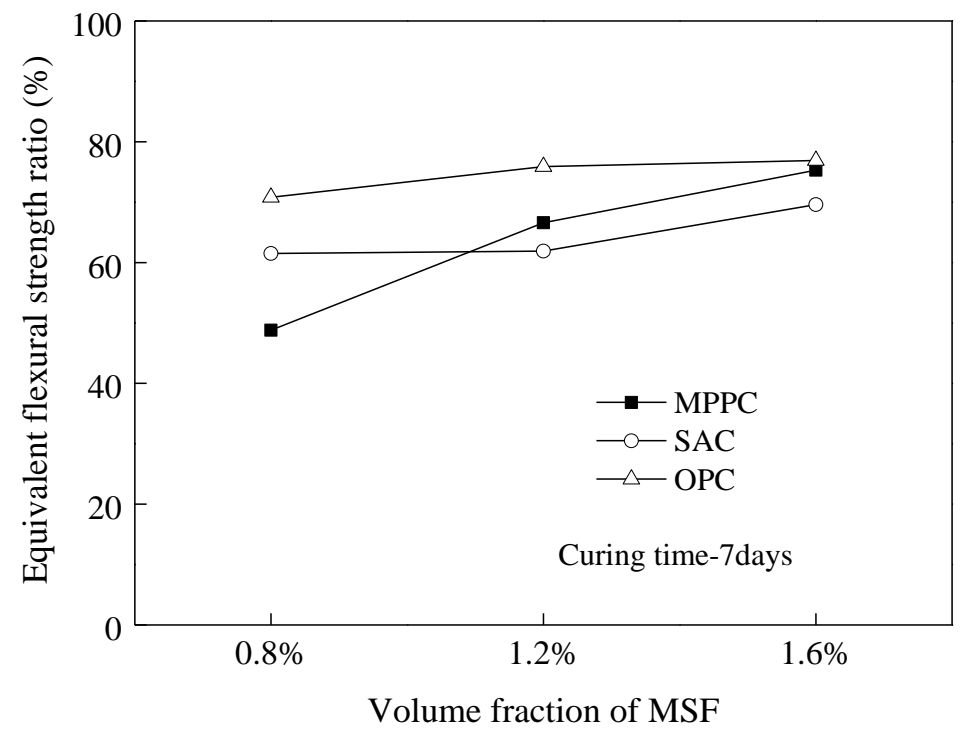

Figure 22 Flexural ductility of different cements based composites with varying volume fraction of MSF cured for 7days 


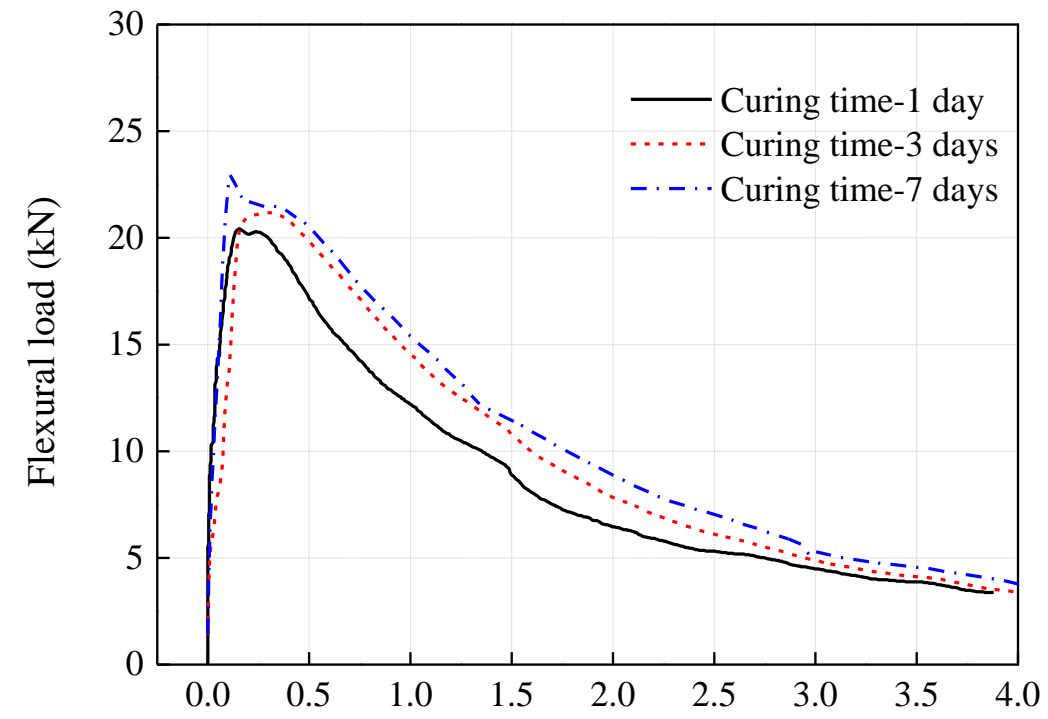

Midspan deflection (mm)

Figure 23 Effect of curing time on flexural load versus midspan deflection of MSFRMC with $1.2 \%$ MSF by volume (Group M-F-1.2\%) 


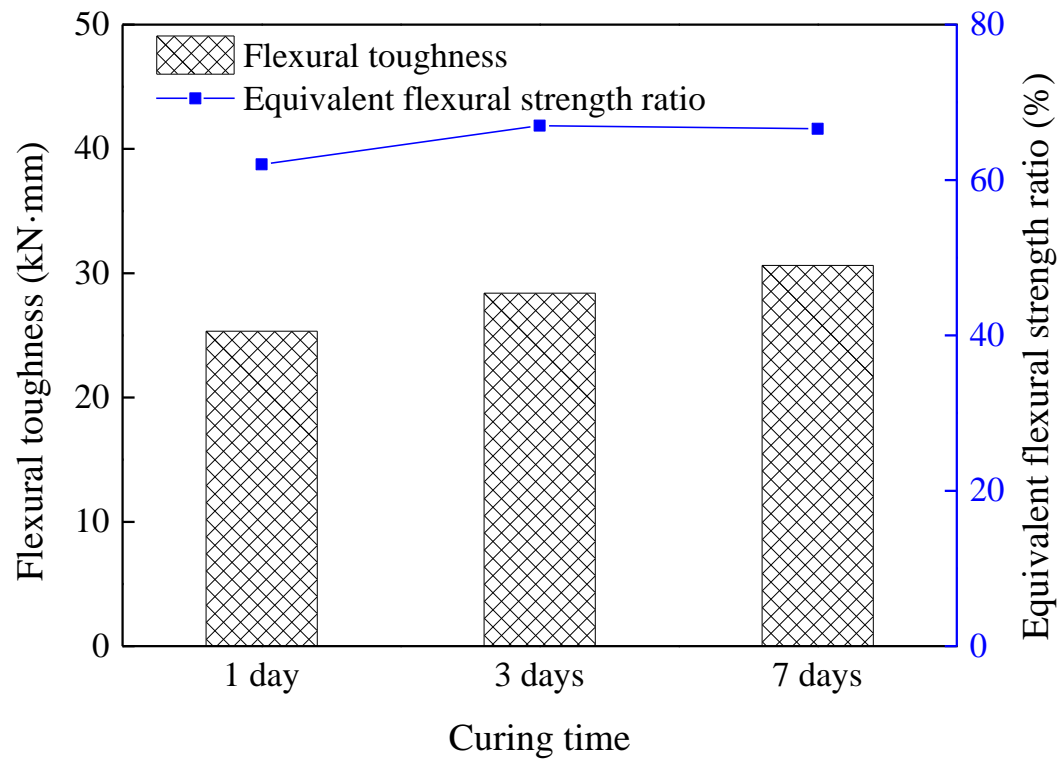

788

789

790

Figure 24 Effect of curing time on flexural toughness and ductility of MSFRMC with $1.2 \%$ MSF by volume (Group M-F-1.2\%) 